\title{
Bile Acid-Based Cyclic Bisbenzimidazolium Receptors for Anion Recognition: Highly Improved Receptors for Fluoride and Chloride ions
}

\author{
Vijay K. Khatri, Mamta Chahar, K. Pavani, ${ }^{\prime}$ and Pramod S. Pandey*
}

Department of Chemistry, Indian Institute of Technology Delhi, Hauz Khas, New Delhi.

pramod@.chemistry.iitd.ac.in

$$
\text { 110016, India }
$$

*Corresponding author: phone: (+91)11-26581506, fax: $(+91) 11-26582037$.

$\uparrow$ Contributed in analysis of crystallographic data.

\section{Supporting Information}

\section{Table of contents}

Page S2-S3: Spectral data for compounds 6, 7, 8 and 10

Page S4-Figure 1: ${ }^{1} \mathrm{H}$ NMR spectrum of 6- $(\mathrm{Br})_{2}$; Figure 2: ${ }^{13} \mathrm{C}$ NMR spectrum of 6-( $\left.\mathrm{Br}\right)_{2}$ Page S5- Figure 3: Mass spectrum of 6-(Br $)_{2}$; Figure 4: ${ }^{1} \mathrm{H}$ NMR spectrum of 6- $\left(\mathrm{PF}_{6}\right)_{2}$ Page S6- Figure 5: Mass spectrum of 6-( $\left(\mathrm{PF}_{6}\right)_{2}$; Figure 6: ${ }^{1} \mathrm{H}$ NMR spectrum of 7-(Br $)_{2}$ Page S7- Figure 7: ${ }^{13} \mathrm{C}$ NMR spectrum of 7-(Br $)_{2}$; Figure 8: Mass spectrum of 7-( $\left.\mathrm{Br}\right)_{2}$ Page S8- Figure 9: ${ }^{1} \mathrm{H}$ NMR spectrum of 7- $\left(\mathrm{PF}_{6}\right)_{2}$; Figure 10: Mass spectrum of 7-( $\left.\mathrm{PF}_{6}\right)_{2}$ Page S9-Figure 11: ${ }^{1} \mathrm{H}$ NMR spectrum of $8-(\mathrm{Br})_{2}$; Figure 12: ${ }^{13} \mathrm{C}$ NMR spectrum of 8$(\mathrm{Br})_{2}$

Page S10- Figure 13: Mass spectrum of 8-( $\mathrm{Br})_{2}$; Figure 14: ${ }^{1} \mathrm{H}$ NMR spectrum of $8-\left(\mathrm{PF}_{6}\right)_{2}$ Page S11- Figure 15: Mass spectrum of $8-\left(\mathrm{PF}_{6}\right)_{2}$; Figure 16: ${ }^{1} \mathrm{H}$ NMR spectrum of 10$(\mathrm{Br})_{2}$

Page S12-Figure 17: ${ }^{13} \mathrm{C}$ NMR spectrum of 10-( $\left.\mathrm{Br}\right)_{2}$; Figure 18: Mass spectrum of 10$(\mathrm{Br})_{2}$

Page S13-Figure 19: ${ }^{1} \mathrm{H}$ NMR spectrum of 10-( $\left.\mathrm{PF}_{6}\right)_{2}$; Figure 20: Mass spectrum of 10$\left(\mathrm{PF}_{6}\right)_{2}$

Page S14-Figure 21: ${ }^{1} \mathrm{H}$ NMR titration binding isotherm for receptor 6 with tetrabutylammonium fluoride (trihydrate salt); Figure 22: Job's plot showing 1:1 complex formation between receptor 6 and fluoride ion

Page S15-Figure 23: ${ }^{1} \mathrm{H}$ NMR titration binding isotherm for receptor 7 with tetrabutylammonium chloride; Figure 24: Job's plot showing 1:1 complex formation between receptor 7 and chloride ion

Page S16-Figure 25: ${ }^{1} \mathrm{H}$ NMR titration binding isotherm for receptor 8 with tetrabutylammonium chloride; Figure 26: Job's plot showing 1:1 complex formation between receptor 8 and chloride ion

Page S17-Figure 27: ${ }^{1} \mathrm{H}$ NMR titration binding isotherm for receptor 10 with tetrabutylammonium chloride; Figure 28: Job's plot showing 1:1 complex formation between receptor 10 and chloride ion 


\section{Spectral Data for Compounds 6-10}

Compound 6-(Br)2: Yield: 72\%; MP: $268{ }^{\circ} \mathrm{C}$; IR (KBr) 2941, 2868, 1740, 1621, 1564 $\mathrm{cm}^{-1}$; ${ }^{1} \mathrm{H}$ NMR $\left(300 \mathrm{MHz}, \mathrm{CDCl}_{3}\right.$, TMS) $\delta 0.74$ (s, 3H, 18-Me), 0.88 (s, 3H, 19-Me), $0.91(\mathrm{~d}, 3 \mathrm{H}, J=6 \mathrm{~Hz}, 21-\mathrm{Me}), 1.01-2.34(26 \mathrm{H}$, steroidal $\mathrm{H}), 3.69\left(\mathrm{~s}, 3 \mathrm{H}, \mathrm{OCH}_{3}\right), 4.71$ $(3 \beta-\mathrm{H}), 4.92\left(\mathrm{~d}, 1 \mathrm{H}, J=18.0 \mathrm{~Hz}, \mathrm{OCOCH}_{2}\right), 5.20\left(\mathrm{~m}, 2 \mathrm{H}, \mathrm{OCOCH}_{2} 12 \beta-\mathrm{H}\right), 5.67-5.90$ $\left(\mathrm{m}, 4 \mathrm{H}, 2 \mathrm{X}\right.$ benzylic $\left.\mathrm{CH}_{2}\right), 6.28\left(\mathrm{~d}, 1 \mathrm{H}, J=18.0 \mathrm{~Hz}, \mathrm{OCOCH}_{2}\right), 6.38(\mathrm{~d}, 1 \mathrm{H}, J=18.0$ $\left.\mathrm{Hz}, \mathrm{OCOCH}_{2}\right), 7.36-7.74(\mathrm{~m}, 11 \mathrm{H}, \mathrm{ArH}), 8.08$ (m, 2H, ArH), 8.7 (s,1H, ArH), 10.64 (s, $1 \mathrm{H}, \mathrm{BIH}-2), 10.94$ (s, 1H, BIH-2). ${ }^{13} \mathrm{C} \mathrm{NMR}\left(75 \mathrm{MHz}, \mathrm{CDCl}_{3}, \mathrm{TMS}\right) \delta 12.17,17.71$, $22.45,22.68,23.18,25.25,25.55,25.88,26.44,26.78,27.23,30.58,30.97,31.19,33.65$, $33.88,34.27,34.50,35.21,41.31,45.08,47.42,48.24,49.22,50.59,50.98,51.52,112.58$, $113.18,113.86,127.19,127.32,131.10,131.22$, 131.39, 131.48, 131.82, 132.84, 133.61, 143.02, 143.82, 165.15, 165.33,174.45; HRMS $\left(\mathrm{ES}^{+}\right)$calcd for $\mathrm{C}_{51} \mathrm{H}_{62} \mathrm{~N}_{4} \mathrm{O}_{6} \mathrm{Br}[\mathrm{M}-\mathrm{Br}]^{+}$, $\mathrm{m} / \mathrm{z}=905.3853$, found 905.3842 .

Compound 6-(PF $)_{2}$ : MP: $206{ }^{\circ} \mathrm{C}$; IR (KBr) 2925, 1740, 1615, $1573 \mathrm{~cm}^{-1} ;{ }^{1} \mathrm{H}$ NMR (300 MHz, CDCl 3 , TMS) $\delta 0.74$ (s, 3H, 18-Me), 0.87 (brs, 6H, 19-Me, 21-Me), 1.09-2.33 $\left(26 \mathrm{H}\right.$, steroidal H), 3.69 (s, 3H, $\left.\mathrm{OCH}_{3}\right), 4.63(\mathrm{~m}, 1 \mathrm{H}, 3 \beta-\mathrm{H}), 4.92-5.60(\mathrm{~m}, 9 \mathrm{H}, 12 \beta-\mathrm{H}, 2 \mathrm{X}$ $\mathrm{OCOCH}_{2}, 2 \mathrm{X}$ benzylic $\mathrm{CH}_{2}$ ), 7.30-8.02 (m, 12H, ArH), 8.99 (brs, 1H, BIH-2), 9.23 (brs, $1 \mathrm{H}, \mathrm{BIH}-2)$; HRMS (ES ${ }^{+}$calcd for $\mathrm{C}_{51} \mathrm{H}_{62} \mathrm{~N}_{4} \mathrm{O}_{6} \mathrm{~F}_{6} \mathrm{P}\left(\mathrm{M}-\mathrm{PF}_{6}^{+}\right), \mathrm{m} / \mathrm{z}=971.4311$, found 971.4319 .

Compound 7-(Br) ${ }_{2}$ : Yield: 70\% MP: $274^{\circ} \mathrm{C}$; IR (KBr) 2942, 2862, 1739, 1621, $1564 \mathrm{~cm}^{-}$ ; ; ${ }^{1} \mathrm{H}$ NMR (300 MHz, CDCl 3 , TMS) $\delta 0.75$ (s, 3H, 18-Me), 0.86 (s, 3H, 19-Me), 0.91 $(\mathrm{d}, J=6 \mathrm{~Hz}, 3 \mathrm{H}, 21-\mathrm{Me}), 1.01-2.32\left(26 \mathrm{H}\right.$, steroidal H), $3.68\left(\mathrm{~s}, 3 \mathrm{H}, \mathrm{OCH}_{3}\right), 4.56(3 \beta-\mathrm{H})$, $4.97\left(\mathrm{~d}, 1 \mathrm{H}, J=18.0, \mathrm{OCOCH}_{2}\right), 5.07$ (d, 1H, $\left.J=18.0, \mathrm{OCOCH}_{2}\right), 5.21(\mathrm{~s}, 1 \mathrm{H}, 12 \beta-\mathrm{H})$, 5.74-5.96 (m, 4H, 2X benzylic $\left.\mathrm{CH}_{2}\right), 6.30\left(\mathrm{~d}, 1 \mathrm{H}, J=18.0, \mathrm{OCOCH}_{2}\right), 6.93(\mathrm{~d}, 1 \mathrm{H}, J=$ 18.0, $\left.\mathrm{OCOCH}_{2}\right), 7.44-7.84(\mathrm{~m}, 12 \mathrm{H}, \mathrm{ArH}), 8.40(\mathrm{~m}, 2 \mathrm{H}, \mathrm{ArH}), 10.50(\mathrm{~s}, 1 \mathrm{H}, \mathrm{BIH}-2)$, $10.64(\mathrm{~s}, 1 \mathrm{H}, \mathrm{BIH}-2) .{ }^{13} \mathrm{C} \mathrm{NMR}\left(75 \mathrm{MHz}, \mathrm{CDCl}_{3}, \mathrm{TMS}\right) \delta 12.32,17.97,22.74,23.35$, 25.67, 26.76, 27.39, 30.72, 31.23, 34.00, 34.18, 34.71, 35.45, 41.53, 45.26, 47.74, 48.06, 49.12, 51.64, 51.78, 51.94, 112.38, 112.67, 114.73, 115.08, 127.41, 127.54, 127.71, $131.19,131.43,131.60,131.92,132.01,132.24,132.75,133.14,142.07,142.32,165.81$, 166.04, 174.58; HRMS (ES ${ }^{+}$calcd for $\mathrm{C}_{51} \mathrm{H}_{62} \mathrm{~N}_{4} \mathrm{O}_{6} \mathrm{Br}(\mathrm{M}-\mathrm{Br})^{+}, \mathrm{m} / \mathrm{z}=905.3853$, found 905.3867 .

Compound 7-(PF $)_{2}$ : MP: $220{ }^{\circ} \mathrm{C}$; IR (KBr) 2930, 1744, 1626, $1570 \mathrm{~cm}^{-1} ;{ }^{1} \mathrm{H}$ NMR (300 $\left.\mathrm{MHz}, \mathrm{CDCl}_{3}, \mathrm{TMS}\right) \delta 0.74$ (s, 3H, 18-Me), 0.88 (brs, 6H, 19-Me, 21-Me), 1.09-2.31 $\left(26 \mathrm{H}\right.$, steroidal H), $3.69\left(\mathrm{~s}, 3 \mathrm{H}, \mathrm{OCH}_{3}\right), 4.39-6.01\left(\mathrm{~m}, 10 \mathrm{H}, 3 \beta-\mathrm{H}, 12 \beta-\mathrm{H}, 2 \mathrm{X} \mathrm{OCOCH}_{2}\right.$, 2X benzylic $\mathrm{CH}_{2}$ ), 7.30-8.01 (m, 12H, ArH), 9.15 (brs, 1H, BIH-2), 9.30 (brs, $1 \mathrm{H}, \mathrm{BIH}-$ 2); HRMS (ES ${ }^{+}$) calcd for $\mathrm{C}_{51} \mathrm{H}_{62} \mathrm{~N}_{4} \mathrm{O}_{6} \mathrm{~F}_{6} \mathrm{P}\left(\mathrm{M}-\mathrm{PF}_{6}{ }^{+}\right), \mathrm{m} / \mathrm{z}=971.4311$, found 971.4297 .

Compound 8-(Br)2. Yield: 80\%; MP: $276{ }^{\circ} \mathrm{C}$; IR (KBr) 2940, 2867, 1738, 1618, 1565 $\mathrm{cm}^{-1}$; ${ }^{1} \mathrm{H}$ NMR $\left(300 \mathrm{MHz}, \mathrm{CDCl}_{3}\right.$, TMS) $\delta 0.69$ (s, 3H, 18-Me), 0.86 (d, $J=21 \mathrm{~Hz}, 3 \mathrm{H}, 21-$ $\mathrm{Me}), 0.90$ (s, 3H, 19-Me), 1.27-2.65 (26H, Steroidal H), 3.67 (s, 3H, $\left.\mathrm{OCH}_{3}\right), 4.48$ (br s, $1 \mathrm{H}, 3 \beta-\mathrm{H}), 5.17$ (s, $1 \mathrm{H}, 12 \beta-\mathrm{H}), 5.48-6.00\left(\mathrm{~m}, 5 \mathrm{H}, \mathrm{OCOCH}_{2}, \mathrm{Py} \mathrm{CH}_{2}\right), 6.26(\mathrm{~d}, J=17.1$ $\left.\mathrm{Hz}, 1 \mathrm{H}, \mathrm{OCOCH}_{2}\right), 6.49\left(\mathrm{~d}, J=15.0 \mathrm{~Hz}, 1 \mathrm{H}, \mathrm{OCOCH}_{2}\right), 7.01(\mathrm{~d}, J=15.0 \mathrm{~Hz}, 1 \mathrm{H}$, $\mathrm{OCOCH}_{2}$ ), 7.61-8.34 (s, 7H, PyH, BIH), 10.48 (s, 1H, BIH-2), 10.84 (s, 1H, BIH-2); ${ }^{13} \mathrm{C}$ NMR $\left(75 \mathrm{MHz} \mathrm{CDCl}_{3}\right.$, TMS) $\delta 11.30,12.09,14.19,17.56,18.62,19.30,20.29,22.26$, $22.48,23.11,24.64,24.89,26.15,26.37,27.09,28.91,30.48,30.64,31.21,33.80,33.92$, 
$34.55,35.91,35.32,35.91,41.19,42.16,44.81,47.30,48.37,48.65,49.20,50.94,51.45$, $51.67,82.19$, , 112.22, 112.84, 113.97, 114.75, 123.86, 124.63, 127.50, 127.68, 127.79, 130.97, 131.11, 131.41, 139.15, 142.95, 151.12, 151.88, 164.55, 174.41; TOF MS (ES $\left.{ }^{+}\right)$: 908.2667 [M-Br] $]^{+}$; Anal. Calcd for $\mathrm{C}_{50} \mathrm{H}_{61} \mathrm{Br}_{2} \mathrm{~N}_{5} \mathrm{O}_{6} . \mathrm{CHCl}_{3} \cdot \mathrm{C}_{6} \mathrm{H}_{12} .3 \mathrm{H}_{2} \mathrm{O}: \mathrm{C}, 54.97 ; \mathrm{H}$, 6.47; N, 5.62. Found: C, 54.61; H, 6.32; N, 5.22.

Compound 8-(PF $)_{2}$. MP: $214{ }^{\circ} \mathrm{C}$; IR (KBr) 2951, 1741, 1628, $1570 \mathrm{~cm}^{-1} ;{ }^{1} \mathrm{H}$ NMR (300 MHz, CDCl 3 , TMS) $\delta 0.59$ (s, 3H, 18-Me), 0.72 (s, 3H, 21-Me), 0.95 (s, 3H, 19-

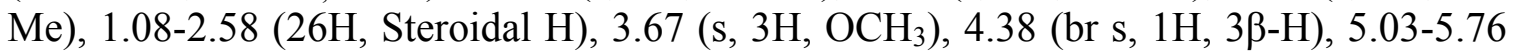
(m, 9H, 2XOCOCH 2 , Py CH $2,12 \beta-H$ ), 7.39-7.81 (s, 7H, PyH, BIH), 9.00 (s, 1H, BIH-2), $9.13(\mathrm{~s}, \quad 1 \mathrm{H}, \quad \mathrm{BIH}-2)$; TOF $\mathrm{MS}\left(\mathrm{ES}^{+}\right)$: $972.1830 \quad\left[\mathrm{M}_{-} \mathrm{PF}_{6}\right]^{+}$; Anal.Calcd for $\mathrm{C}_{50} \mathrm{H}_{61} \mathrm{~F}_{12} \mathrm{~N}_{5} \mathrm{O}_{6} \mathrm{P}_{2} .3 \mathrm{CH}_{3} \mathrm{OH} . \mathrm{C}_{6} \mathrm{H}_{12} .4 \mathrm{H}_{2} \mathrm{O}: \mathrm{C}, 51.98 ; \mathrm{H}, 7.05 ; \mathrm{N}, 5.05$. Found: $\mathrm{C}, 52.18 ; \mathrm{H}$, $6.58 ; \mathrm{N}, 4.64$.

Compound 10-(Br) 2 . Yield: 85 \%; MP: $212^{\circ} \mathrm{C}$. IR (KBr) 3077, 2927, 2863, 1740, 1621, $1568 \mathrm{~cm}^{-1} ;{ }^{1} \mathrm{H}$ NMR (300 MHz, $\mathrm{CDCl}_{3}$, TMS) 0.74 (s, 3H, 18-Me), 0.83 (d, J=4.63 Hz, $3 \mathrm{H}, 21-\mathrm{Me}), 0.91$ (s, 3H, 19-Me), 1.10-2.22 (26H, Steroidal H), $3.66\left(\mathrm{~s}, 3 \mathrm{H}, \mathrm{OCH}_{3}\right), 4.35$

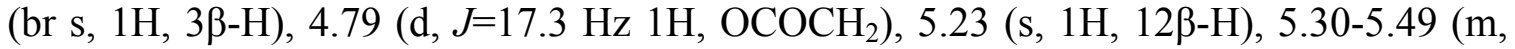
4H, Py $\mathrm{CH}_{2}$ ), 5.92 (d, $\left.J=17.4 \mathrm{~Hz}, 1 \mathrm{H}, \mathrm{OCOCH}_{2}\right), 6.28$ (d, J=15.21 Hz, 1H, $\mathrm{OCOCH}_{2}$ ), $6.65\left(\mathrm{~d}, J=15.4 \mathrm{~Hz}, 1 \mathrm{H}, \mathrm{OCOCH}_{2}\right), 7.31-7.84$ (s, 6H, PyH, ImH), 8.23 (s, 1H, ImH), 9.76 (s, 1H, ImH-2), 9.87 (s, 1H, ImH-2); ${ }^{13} \mathrm{C}$ NMR (75 MHz, CDCl 3 , TMS) $\delta 11.71,17.04$, 21.81, 22.76, 24.32, 25.55, 25.91, 26.74, 30.04, 30.59, 33.29, 33.41, 34.29, 34.71, 41.46, $44.47,46.67,48.93,49.85,50.36,50.97,52.75,53.11,78.46,80.88,122.66,122.77$, 123.05, 123.24, 137.47, 137.75, 138.49, 151.33, 152.30, 164.72, 165.73, 174.08; HRMS $\left(\mathrm{ES}^{+}\right)$calcd for $\mathrm{C}_{42} \mathrm{H}_{57} \mathrm{~N}_{5} \mathrm{O}_{6} \mathrm{Br}(\mathrm{M}-\mathrm{Br})^{+}, \mathrm{m} / \mathrm{z}=806.3492$, found 806.3486.

Compound 10-(PF $)_{2}$. MP: $110{ }^{\circ} \mathrm{C}$; IR (KBr) 3152, 2926, 1748, 1617, $1571 \mathrm{~cm}^{-1} ;{ }^{1} \mathrm{H}$ NMR (300 MHz, CDCl 3 , TMS) $\delta 0.70$ (s, 3H, 18-Me), 0.79 (s, 3H, 21-Me), $0.88(\mathrm{~s}, 3 \mathrm{H}$,

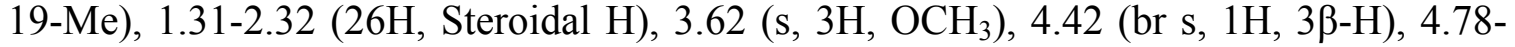
5.57 (m, 9H, OCOCH $\left.2,12 \beta-\mathrm{H}, \mathrm{Py} \mathrm{CH}_{2}\right), 7.32-7.63$ (m, 7H, PyH, ImH), 8.33 (s, 1H, ImH-

2), 8.45 (s, 1H, ImH-2); TOF MS $\left(\mathrm{ES}^{+}\right)$: 872.6094 [M-PF $]^{+}$; Anal. Calcd for $\mathrm{C}_{42} \mathrm{H}_{57} \mathrm{~F}_{12} \mathrm{~N}_{5} \mathrm{O}_{6} \mathrm{P}_{2} . \mathrm{CH}_{3} \mathrm{CN} . \mathrm{H}_{2} \mathrm{O}$ : C, 49.07; H, 5.80; N, 7.80. Found: C, 48.94; H, 5.56; N, 7.55 . 
NMR \& Mass Spectra of Compounds 6-10

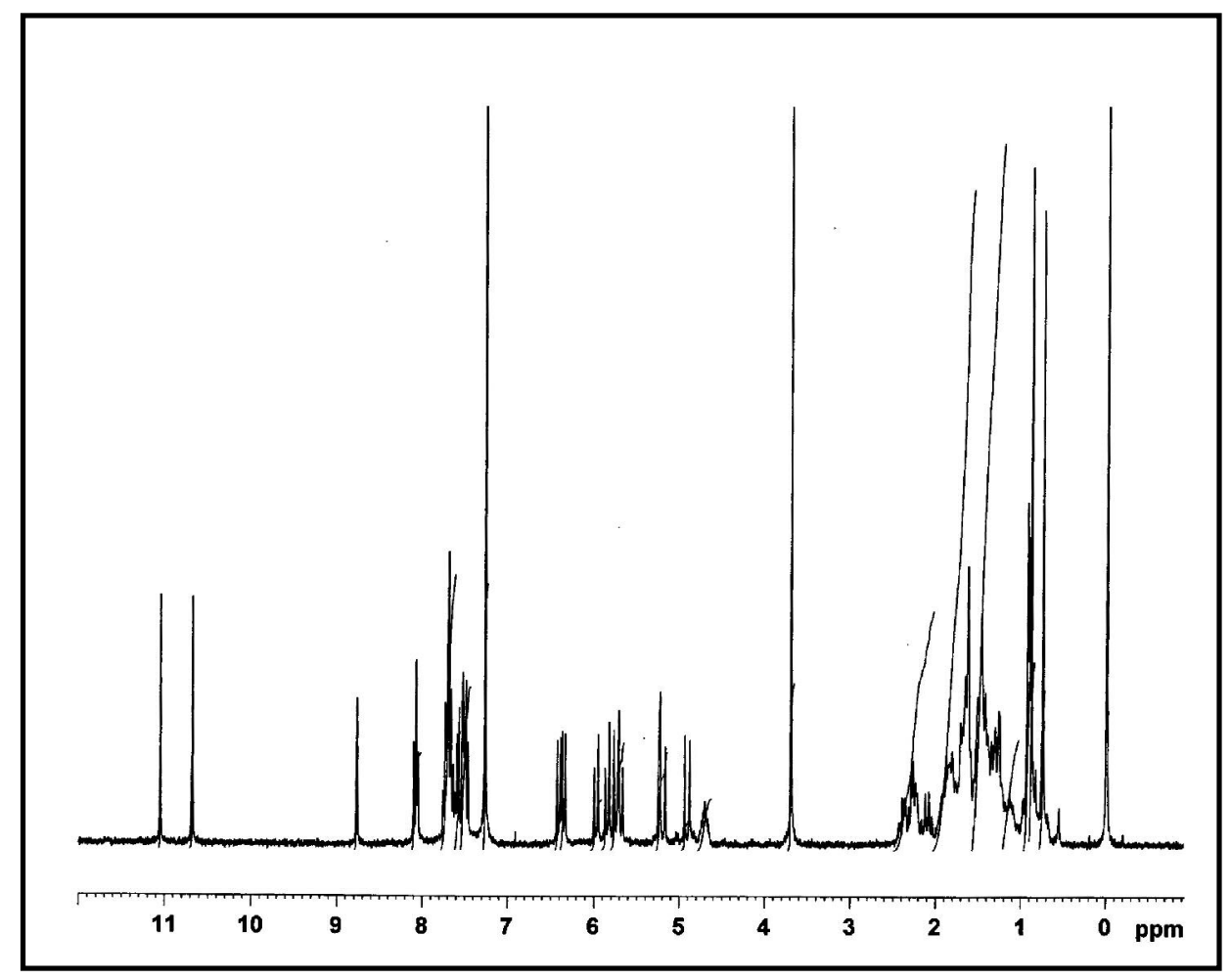

Figure 1: ${ }^{1} \mathrm{H}$ NMR of 6-(Br) $)_{2}$

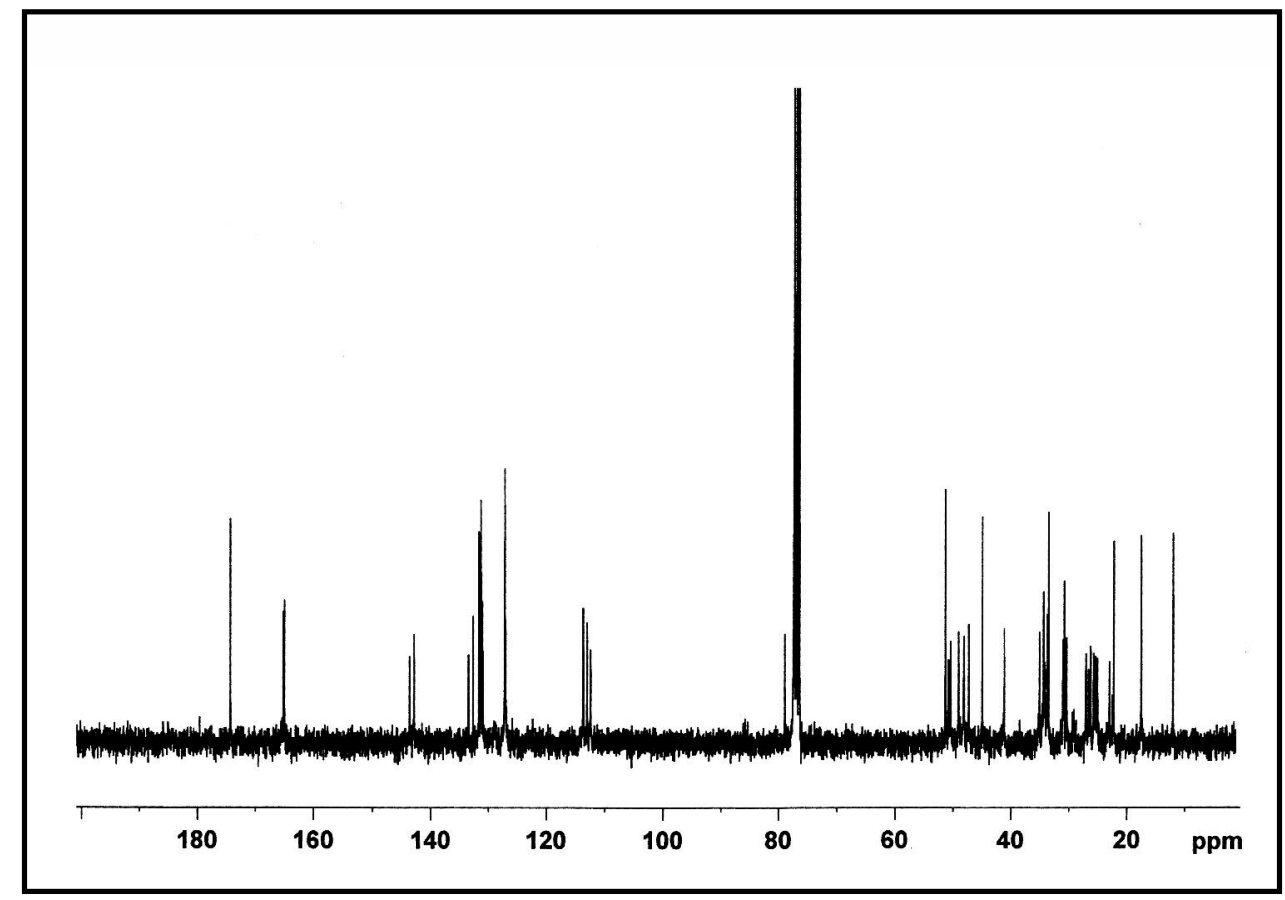

Figure 2: ${ }^{13} \mathrm{C}$ NMR of 6-(Br) $)_{2}$ 


\section{Single Mass Analysis}

Tolerance $=200.0 \mathrm{mDa} / \mathrm{DBE}: \min =-1.5, \max =50.0$

Isotope cluster parameters: Separation $=1.0$ Abundance $=1.0 \%$

Monoisotopic Mass, Odd and Even Electron lons

61 formula(e) evaluated with 1 results within limits (all results (up to 1000) for each mass)

26-Dec-200612:18:25VK-1

12:18:25

KHATRI_VK1 $3(0.056)$ AM (Cen,2, 80.00, Ht,5000.0.0.00,1.00); Sm (Mn, 3×1.00); Cm (1:5)

100 905.3842

1: TOF MS ES+

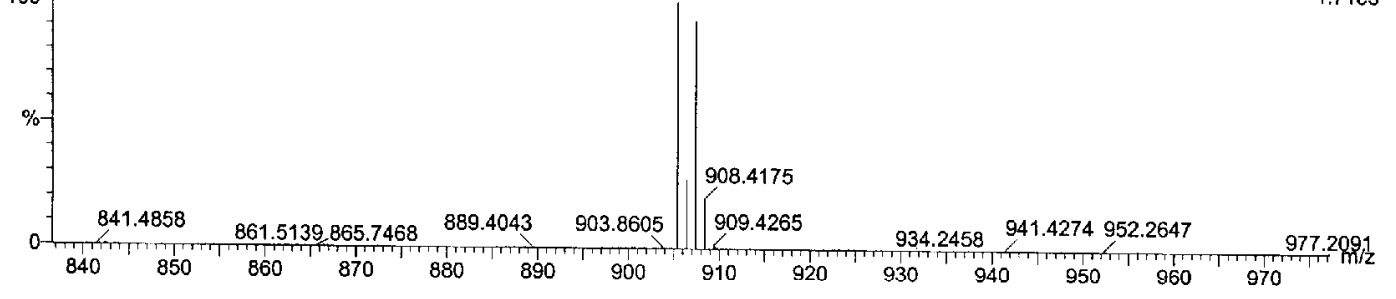

Minimum:

Maximum :

$\begin{array}{lll}200.0 & 5.0 & -1.5 \\ & 50.0\end{array}$

Calc. Mass

$\mathrm{mDa} \quad \mathrm{PPM}$

DBE

Score

Formula

905.3842

905.3853

$-1.1$

$-1.2$

22.5

$\mathrm{C} 51 \mathrm{H} 62$ N4 $06 \mathrm{Br}$

Figure 3: Mass spectrum of 6-(Br)

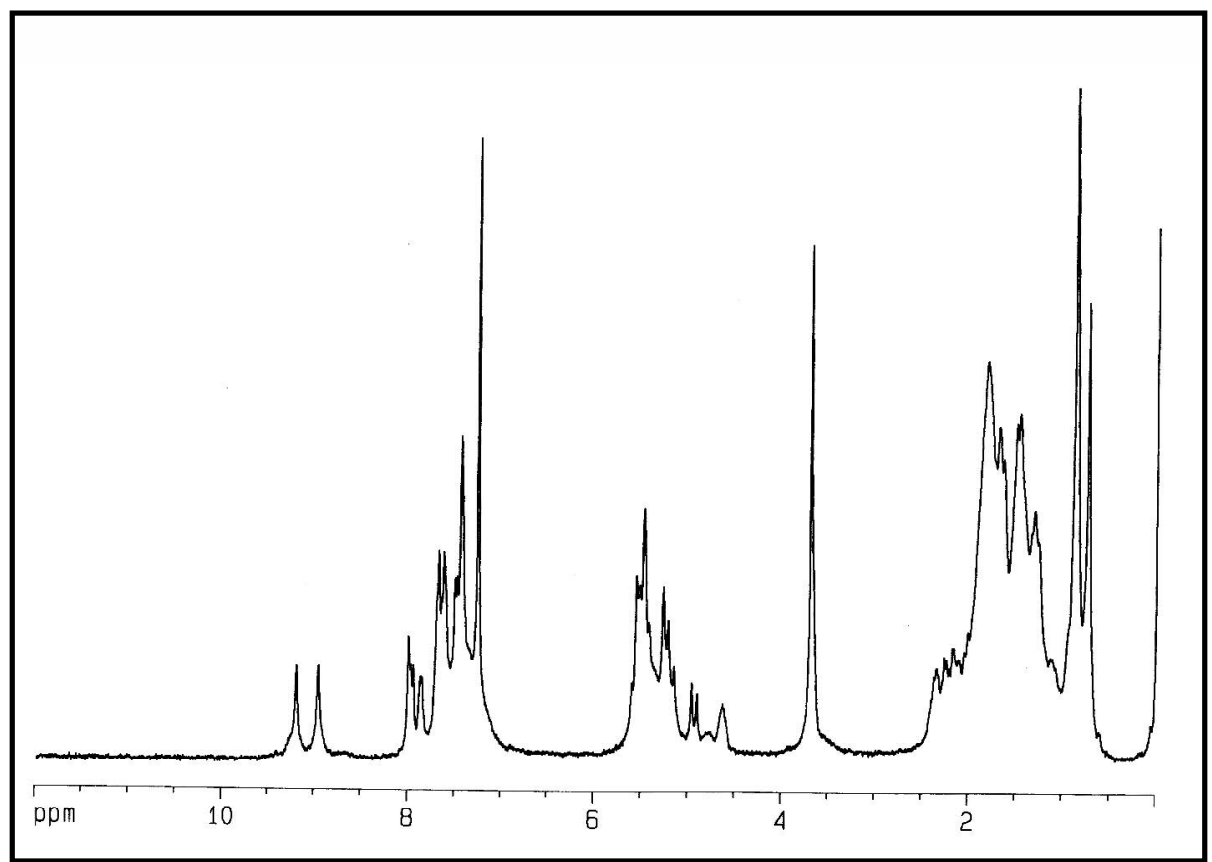

Figure 4: ${ }^{1} \mathrm{H}$ NMR of 6-( $\left(\mathrm{PF}_{6}\right)_{2}$ 


\section{Single Mass Analysis}

Tolerance $=200.0 \mathrm{mDa} / \mathrm{DBE}: \min =-1.5, \max =50.0$

Isotope cluster parameters: Separation $=1.0$ Abundance $=1.0 \%$

Monoisotopic Mass, Odd and Even Electron Ions

469 formula(e) evaluated with 1 results within limits (all results (up to 1000) for each mass)

26-Dec-200613:50:40VK-2

13:50:40

KHATRI_VK2 $1(0.019)$ AM (Cen, 2, 80.00, Ht,5000.0,0.00,1.00); Sm (Mn, 3x1.00); Cm (1:6)

$1007 \quad 971.4319$

1: TOF MS ES+

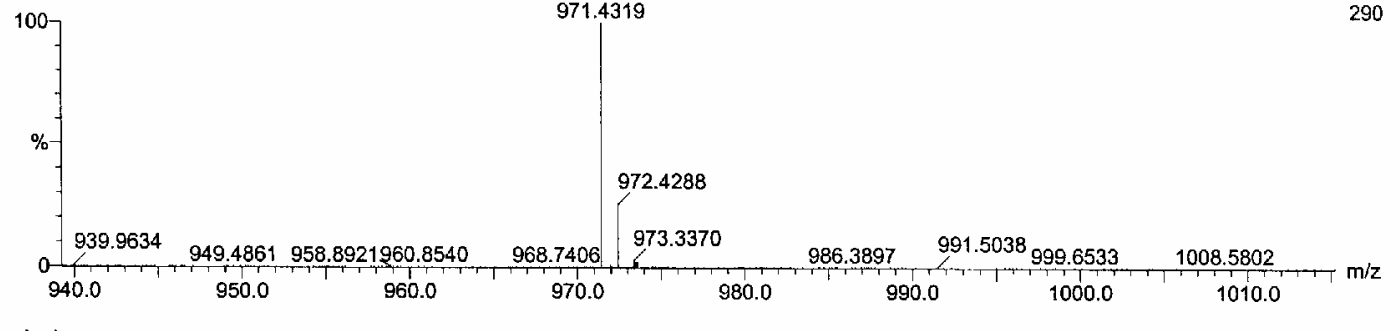

Minimum:

Maximum:

$-1.5$

Mass Calc. Mass mDa PFM DBE Score Formula

$\begin{array}{llllllllllll}971.4319 & 971.4311 & 0.8 & 0.8 & 20.5 & 1 & \text { C51 } & \text { H62 } & \text { N4 } & \text { O6 } & \text { P } & \text { F6 }\end{array}$

Figure 5: Mass spectrum of 6-( $\left(\mathrm{PF}_{6}\right)_{2}$

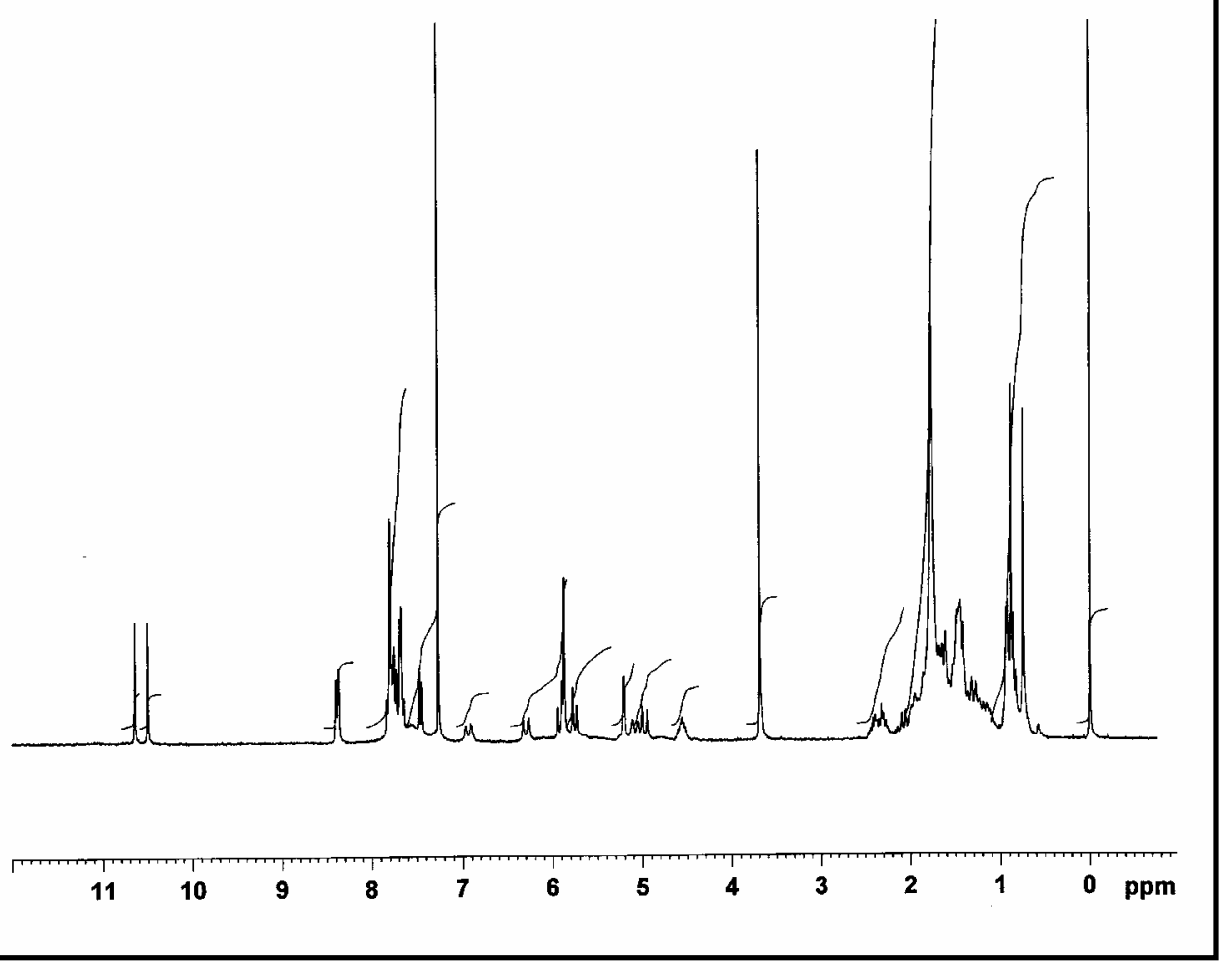

Figure 6: ${ }^{1} \mathrm{H}$ NMR of 7-(Br) 


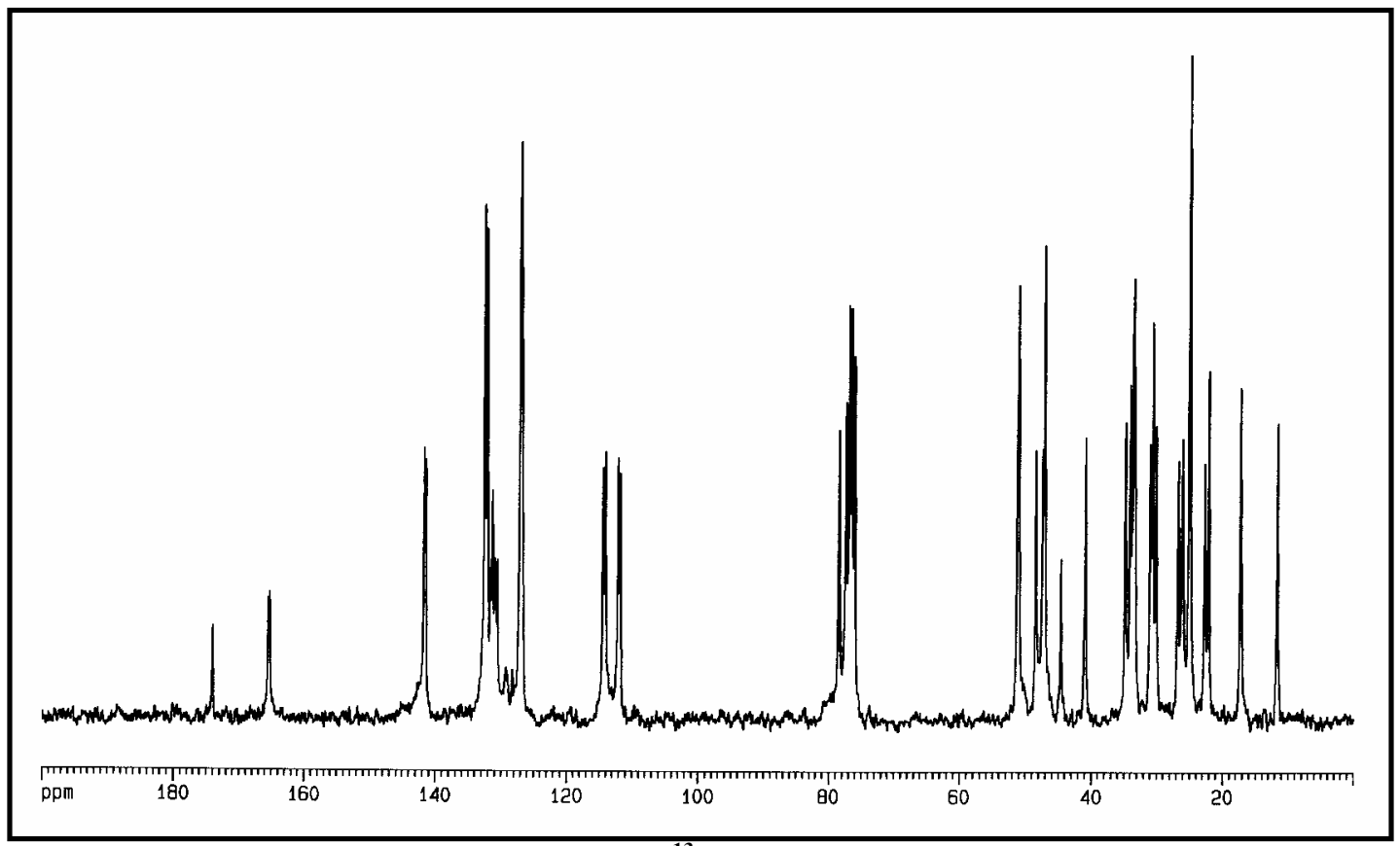

Figure 7: ${ }^{13} \mathrm{C}$ NMR of 7-(Br) ${ }_{2}$

Single Mass Analysis

Tolerance $=200.0 \mathrm{mDa} / \mathrm{DBE}: \min =-1.5, \max =50.0$

Isotope cluster parameters: Separation $=1.0$ Abundance $=1.0 \%$

Monoisotopic Mass, Odd and Even Electron lons

61 formula(e) evaluated with 1 results within limits (all results (up to 1000) for each mass)

24-Jan-200710:40:20VK-1

10:40:20

IITD_VK-1 13 (0.243) AM (Cen,2, 80.00, Ht,5000.0,0.00,1.00); Sm (Mn, 3×1.00); Cm (9:18)

100

$905.3867 \quad 907.3934$

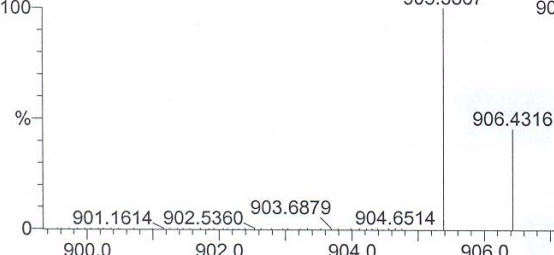

$$
\text { Minimum: }
$$

Minimum:

Maximum

$902.0 \quad 904.0$

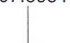

Mass

200.0

5.0

-1.5
50.0

905.3867

905.3853

$\mathrm{mDa}$

PPM

$\mathrm{DBE}$

Score

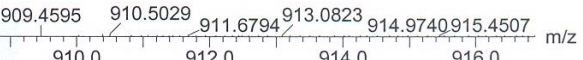

(905.

$1.4 \quad 1.5$

$22.5 \quad 1$

Formula

C51 $\mathrm{H} 62 \quad \mathrm{~N} 4 \quad 06 \quad \mathrm{Br}$

Figure 8: Mass spectrum of 7-(Br) $)_{2}$ 


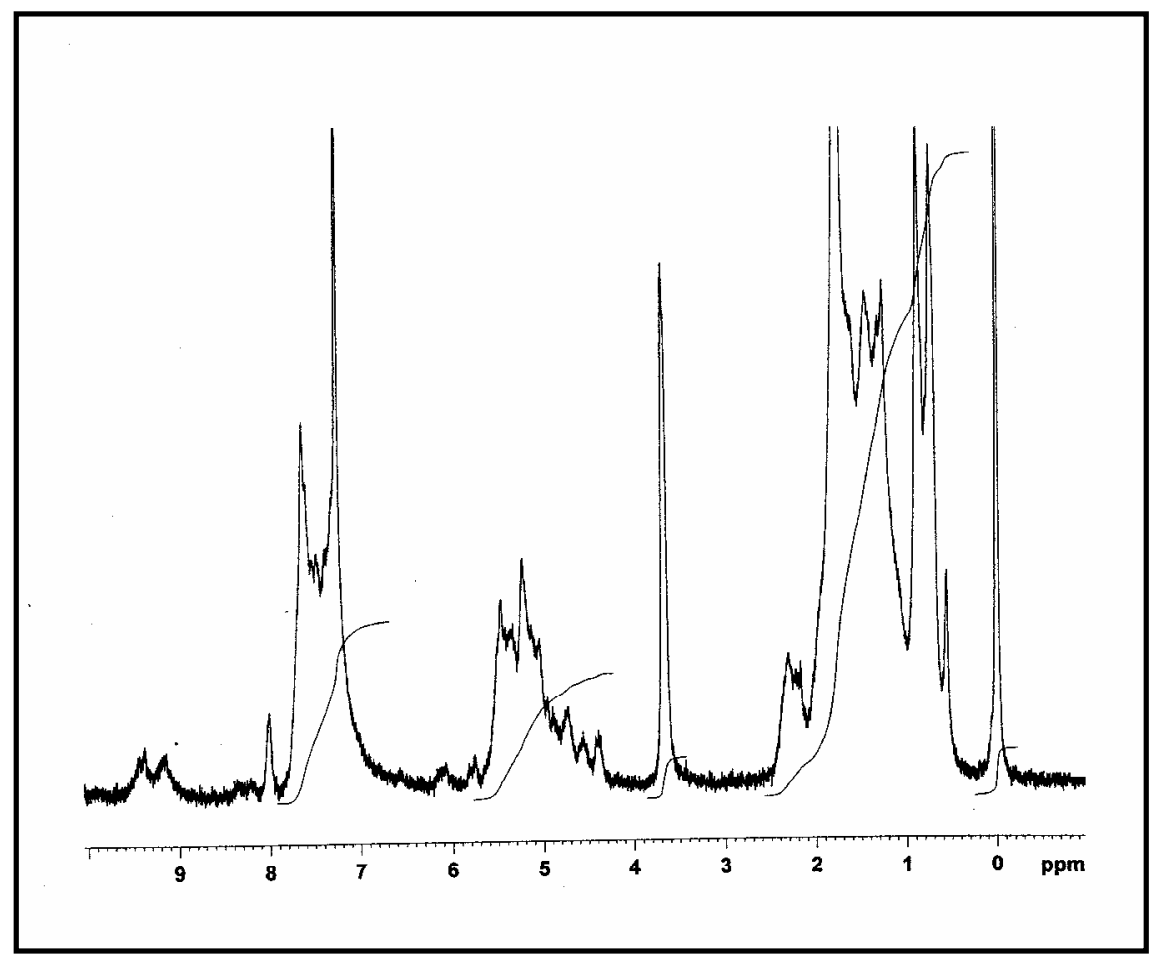

Figure 9: ${ }^{1} \mathrm{H}$ NMR of 7-( $\left.\mathrm{PF}_{6}\right)_{2}$

Elemental Composition Report

Single Mass Analysis

Tolerance $=200.0 \mathrm{mDa} / \mathrm{DBE}: \min =-1.5, \max =50.0$

Isotope cluster parameters: Separation $=1.0$ Abundance $=1.0 \%$

Monoisotopic Mass, Odd and Even Electron lons

469 formula(e) evaluated with 1 results within limits (all results (up to 1000) for each mass)

\section{4-Jan-200711:12:32VK-2}

11:12:32

IITD_VK-2 21 (0.392) AM (Cen,2, 80.00, Ht,5000.0,0.00,1.00); Sm (Mn, 3×1.00); Cm (16:25)

100

100

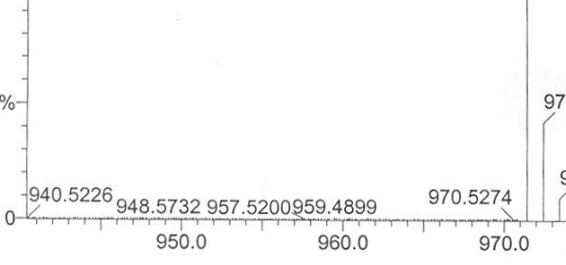

972.4434

973.4521

\section{Minimum:}

Maximum:

$\begin{array}{lll}200.0 \quad 5.0 & -1.5 \\ & & 50.0\end{array}$

Mass

Calc. Mass

mDa PPM

DBE

971.4297

971.4311

$-1.4 \quad-1.4$

$20.5 \quad 1$

Formula

C51 H62 N4 O6 F6 P

Figure 10: Mass spectrum of 7-( $\left.\mathrm{PF}_{6}\right)_{2}$ 


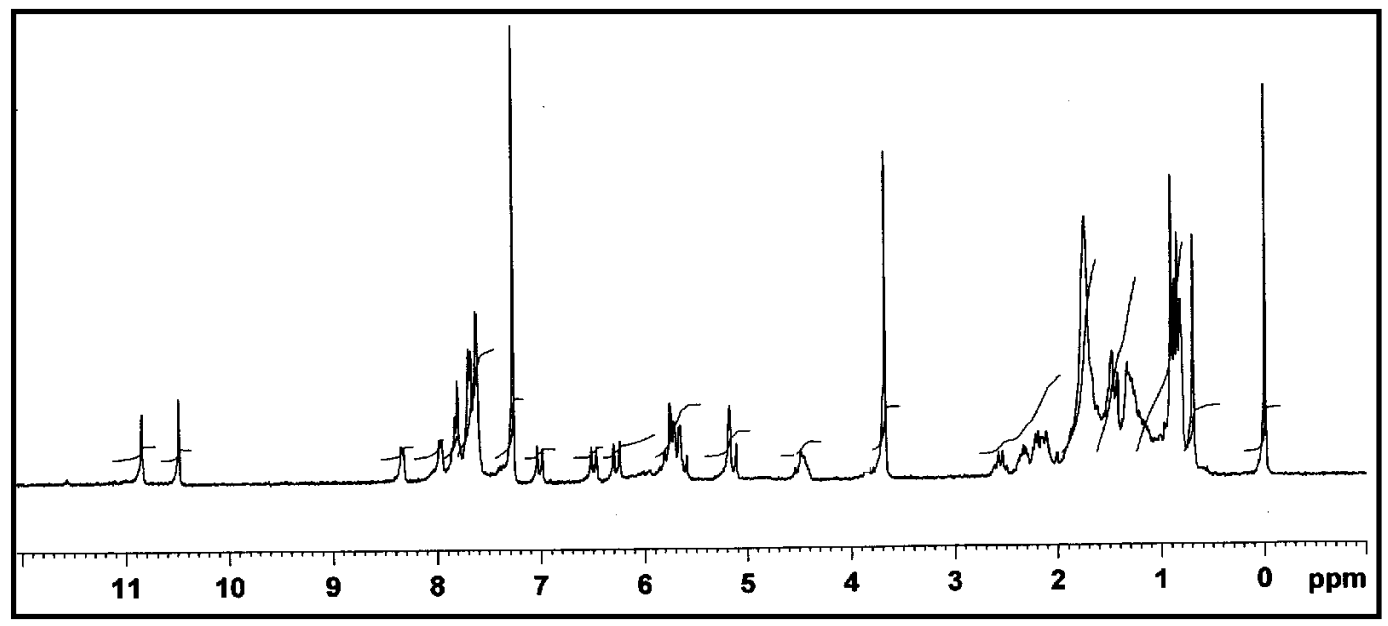

Figure 11: ${ }^{1} \mathrm{H}$ NMR of 8-(Br)

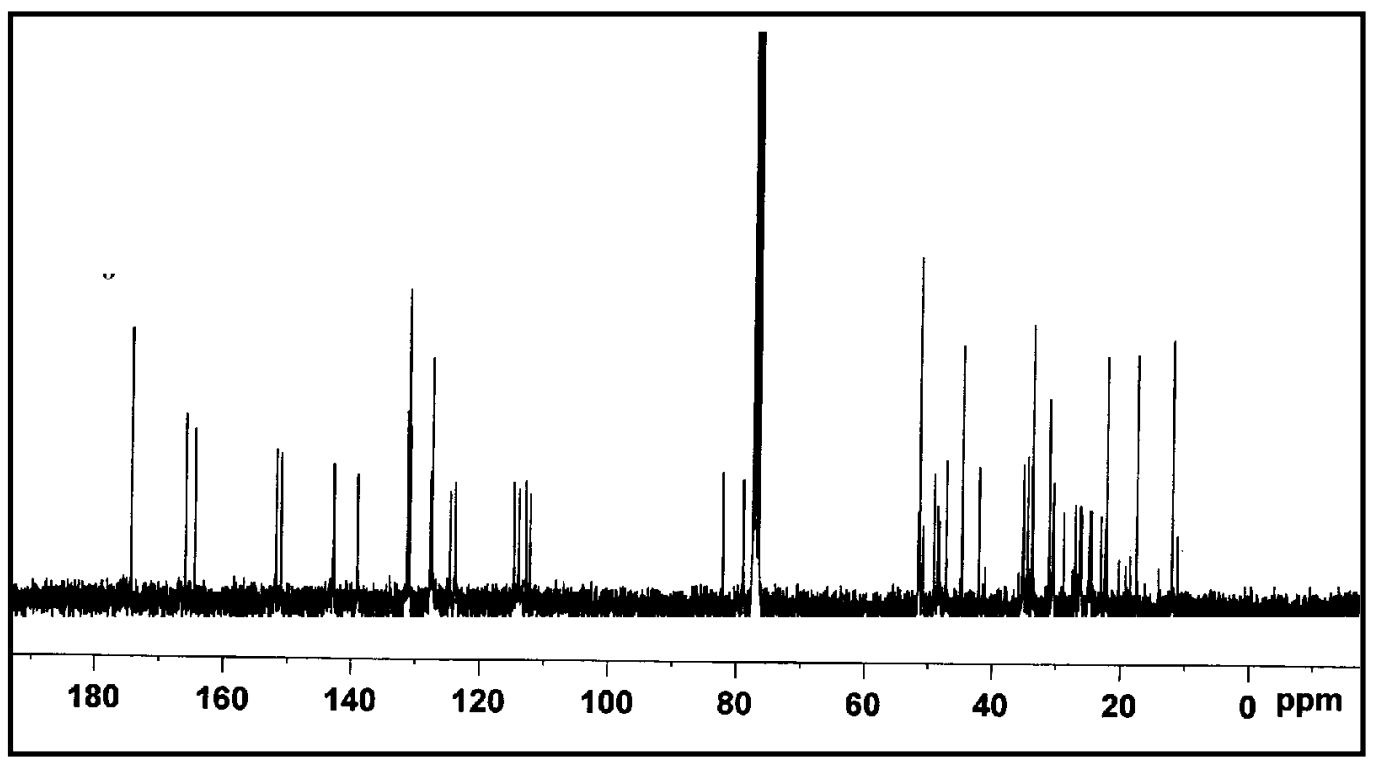

Figure 12: ${ }^{13} \mathrm{C}$ NMR of 8-(Br) ${ }_{2}$ 


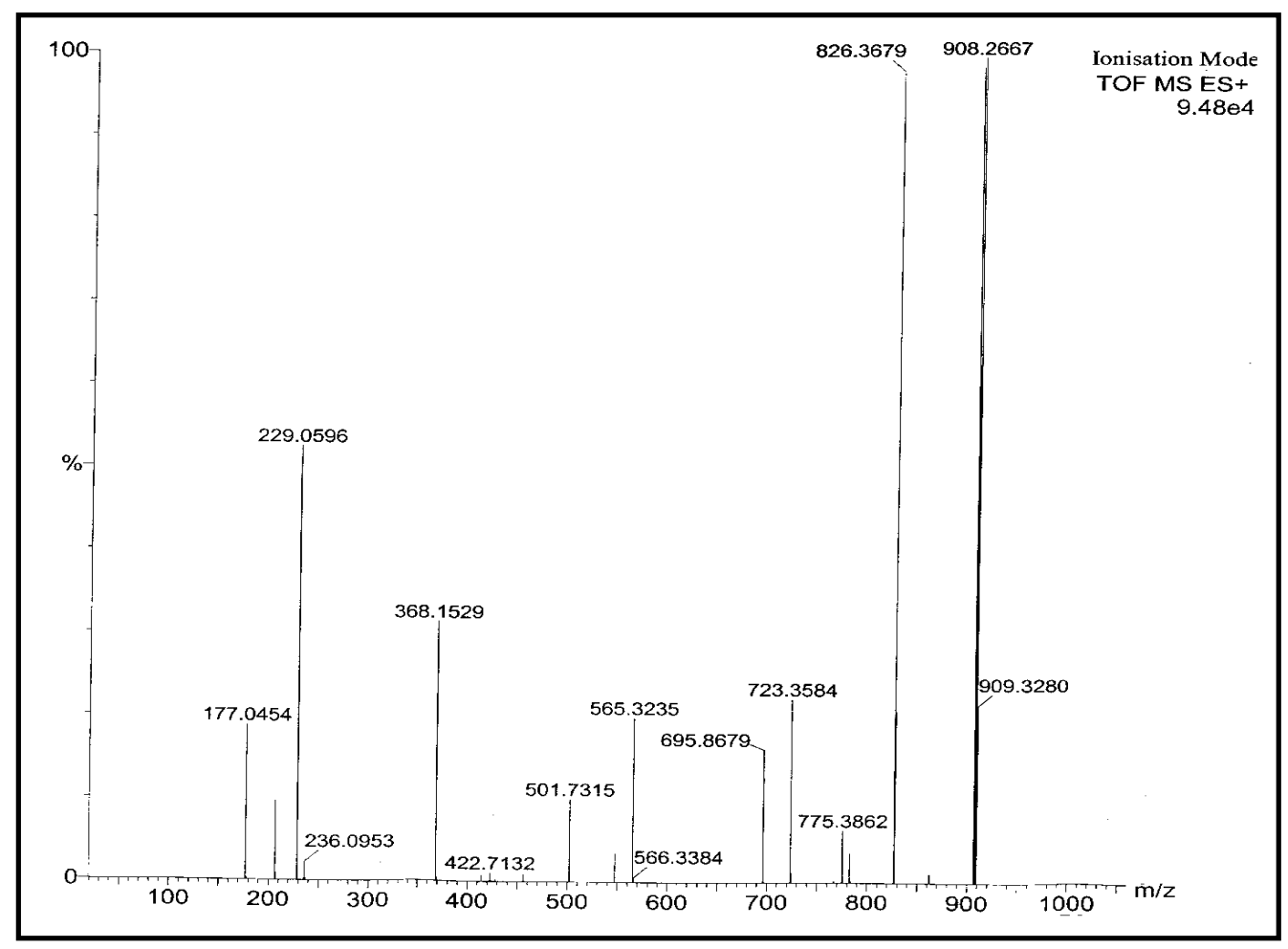

Figure 13: Mass spectrum of 8-(Br)

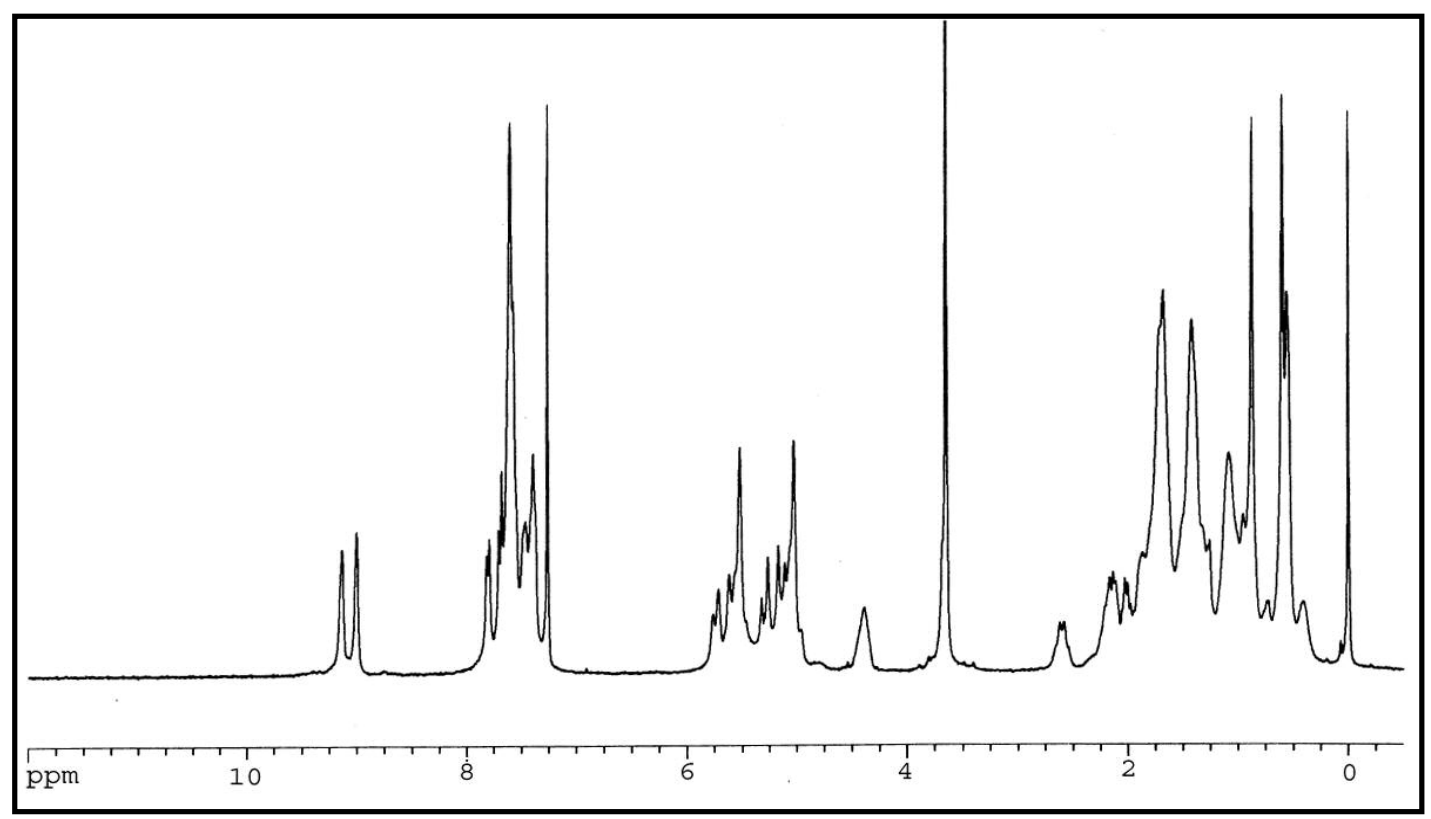

Figure 14: ${ }^{1} \mathrm{H}$ NMR spectrum of 8-( $\left(\mathrm{PF}_{6}\right)_{2}$ 


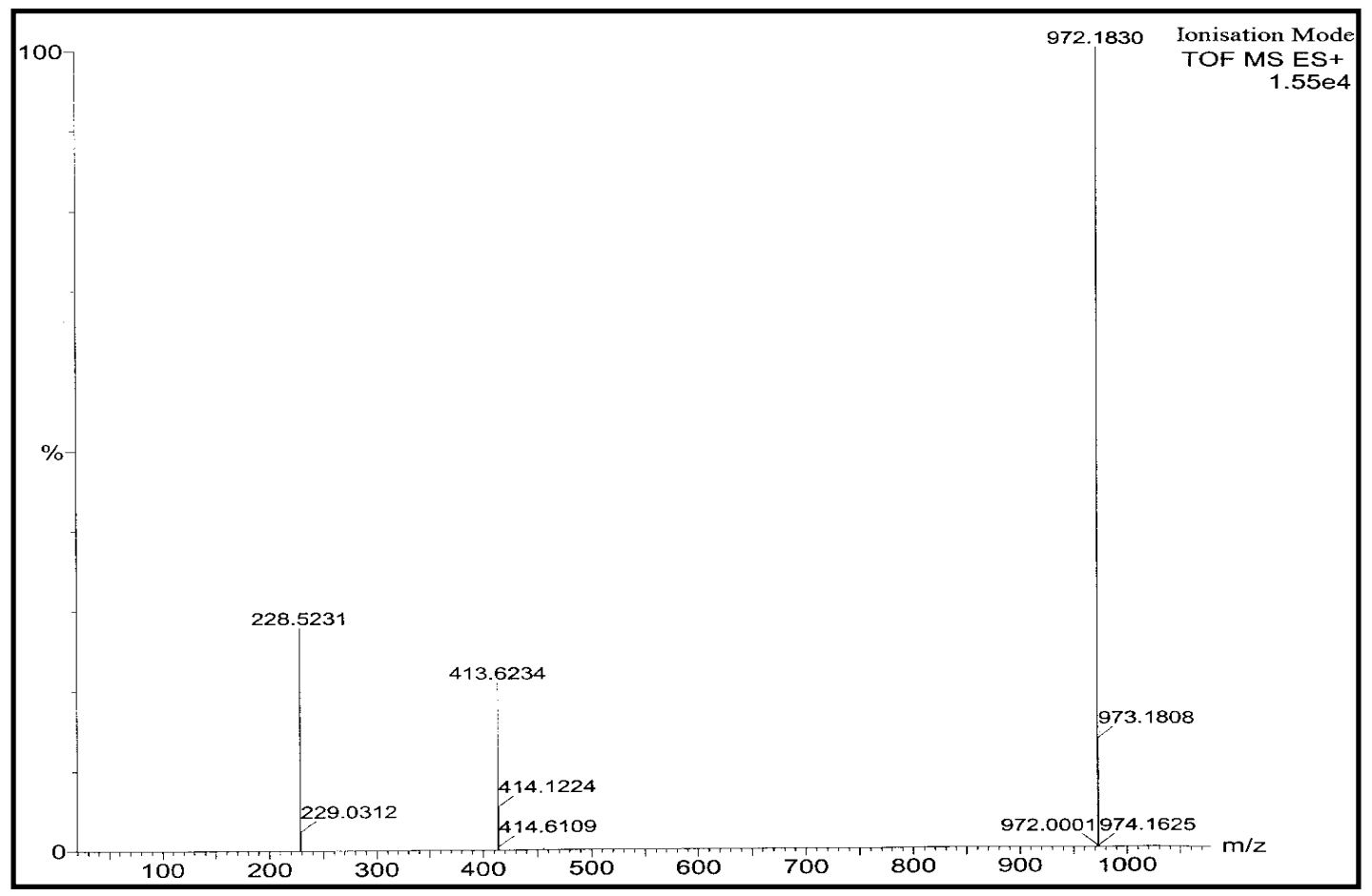

Figure 15: Mass spectrum of 8-( $\left(\mathrm{PF}_{6}\right)_{2}$

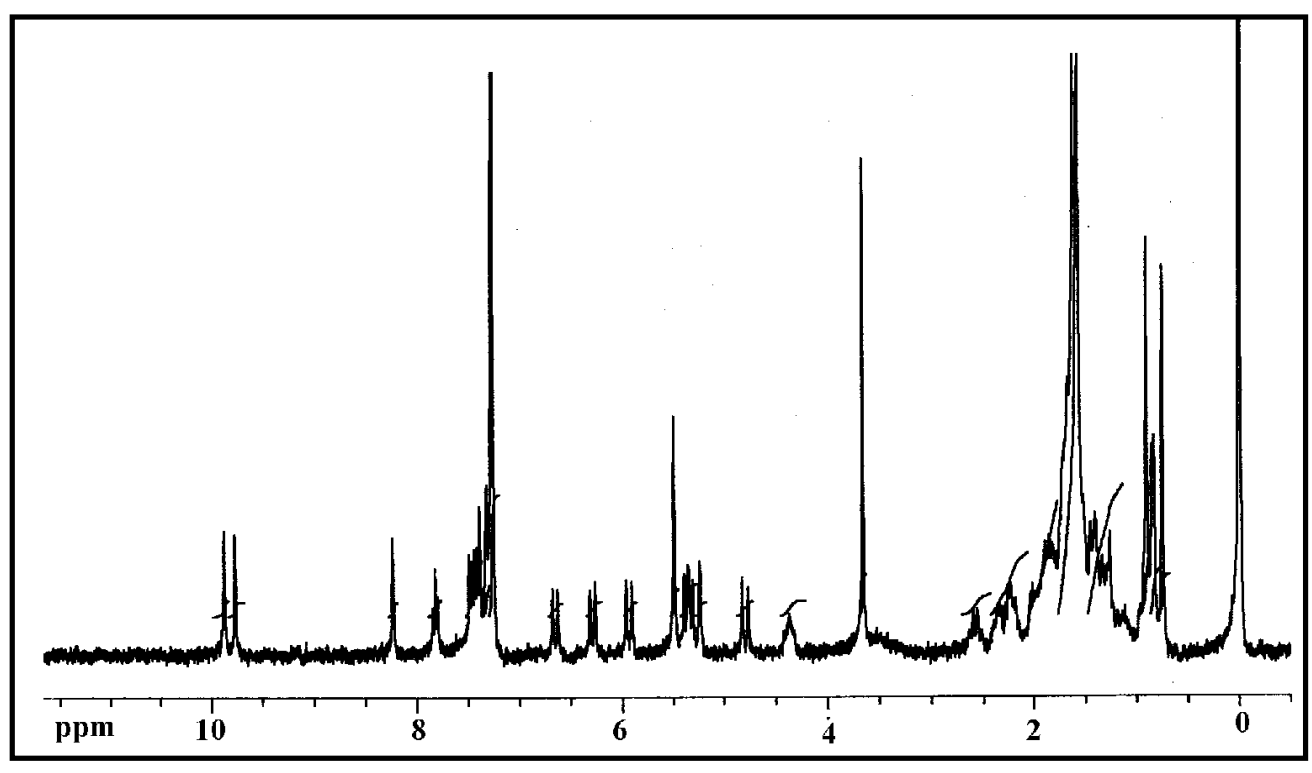

Figure 16: ${ }^{1} \mathrm{H}$ NMR of compound $10-(\mathrm{Br})_{2}$ 


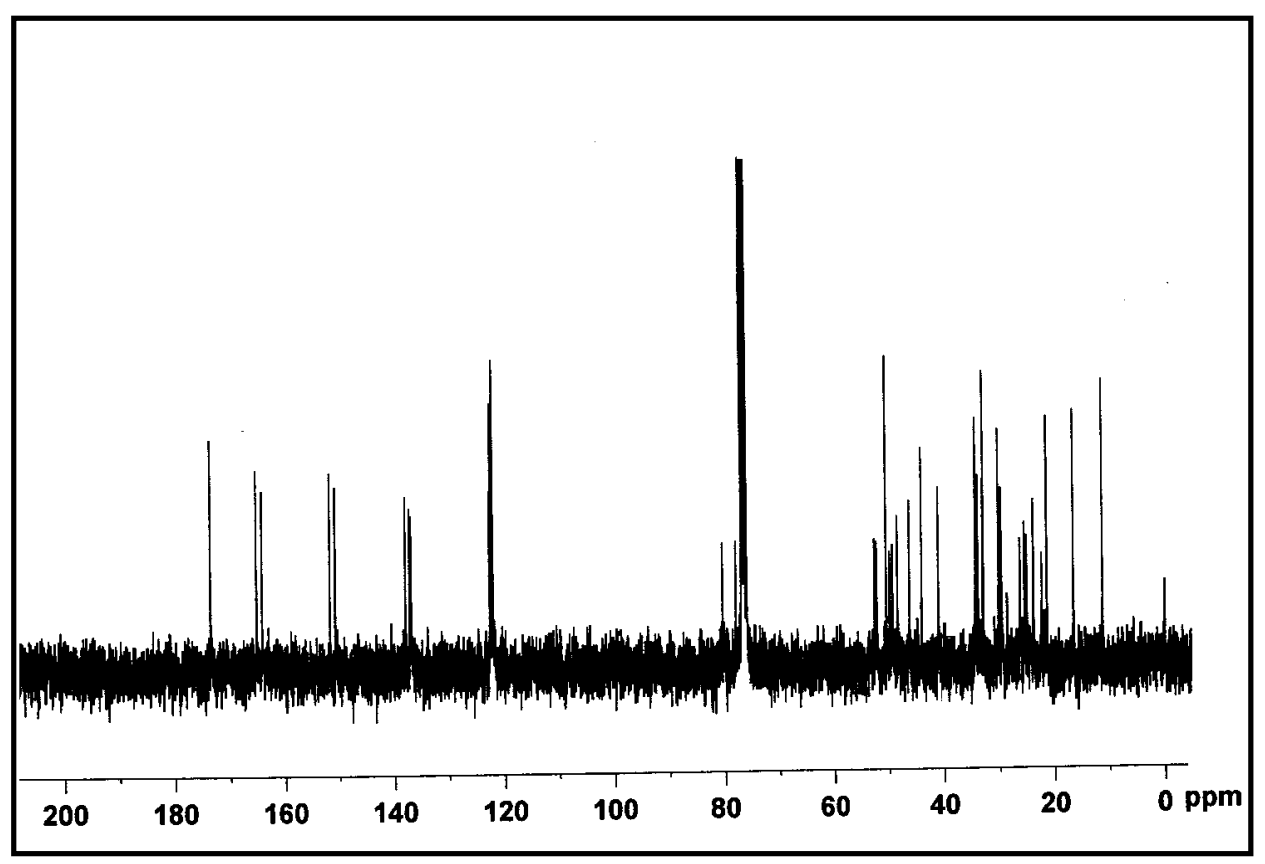

Figure 17: ${ }^{13} \mathrm{C}$ NMR of compound 10-(Br) ${ }_{2}$

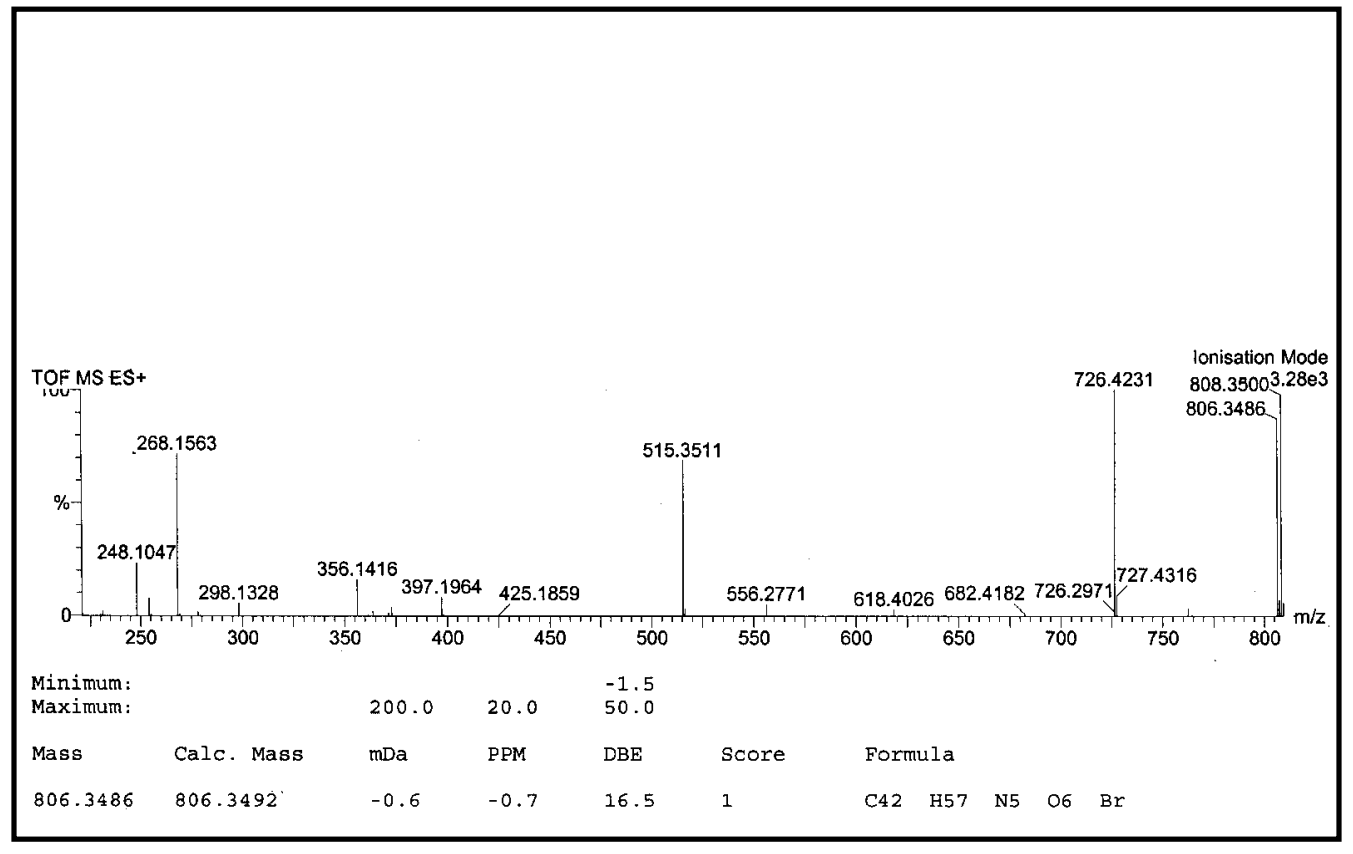

Figure 18: Mass spectrum of compound 10-(Br) 


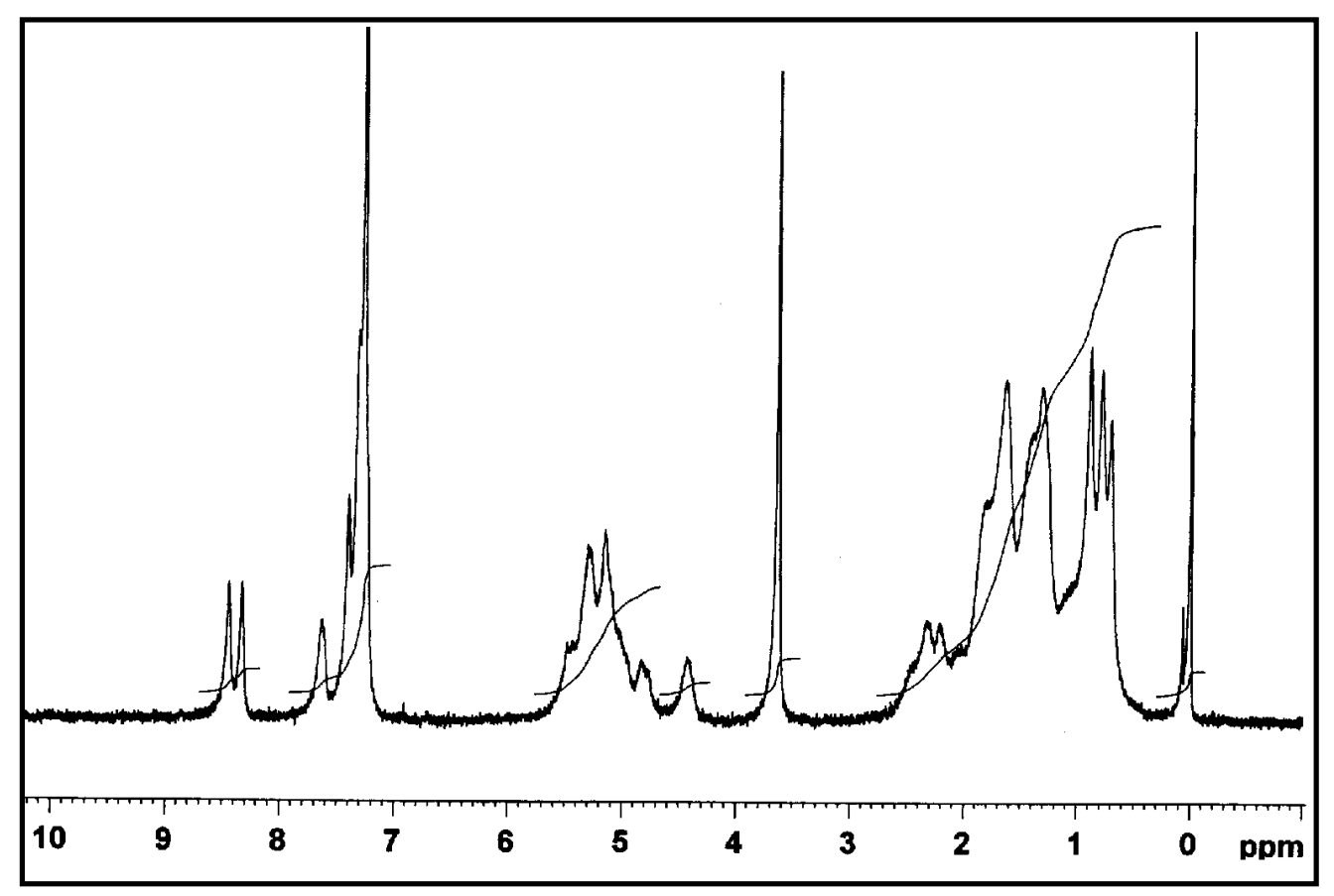

Figure 19: ${ }^{1} \mathrm{H}$ NMR of compound 10-( $\left.\mathrm{PF}_{6}\right)_{2}$

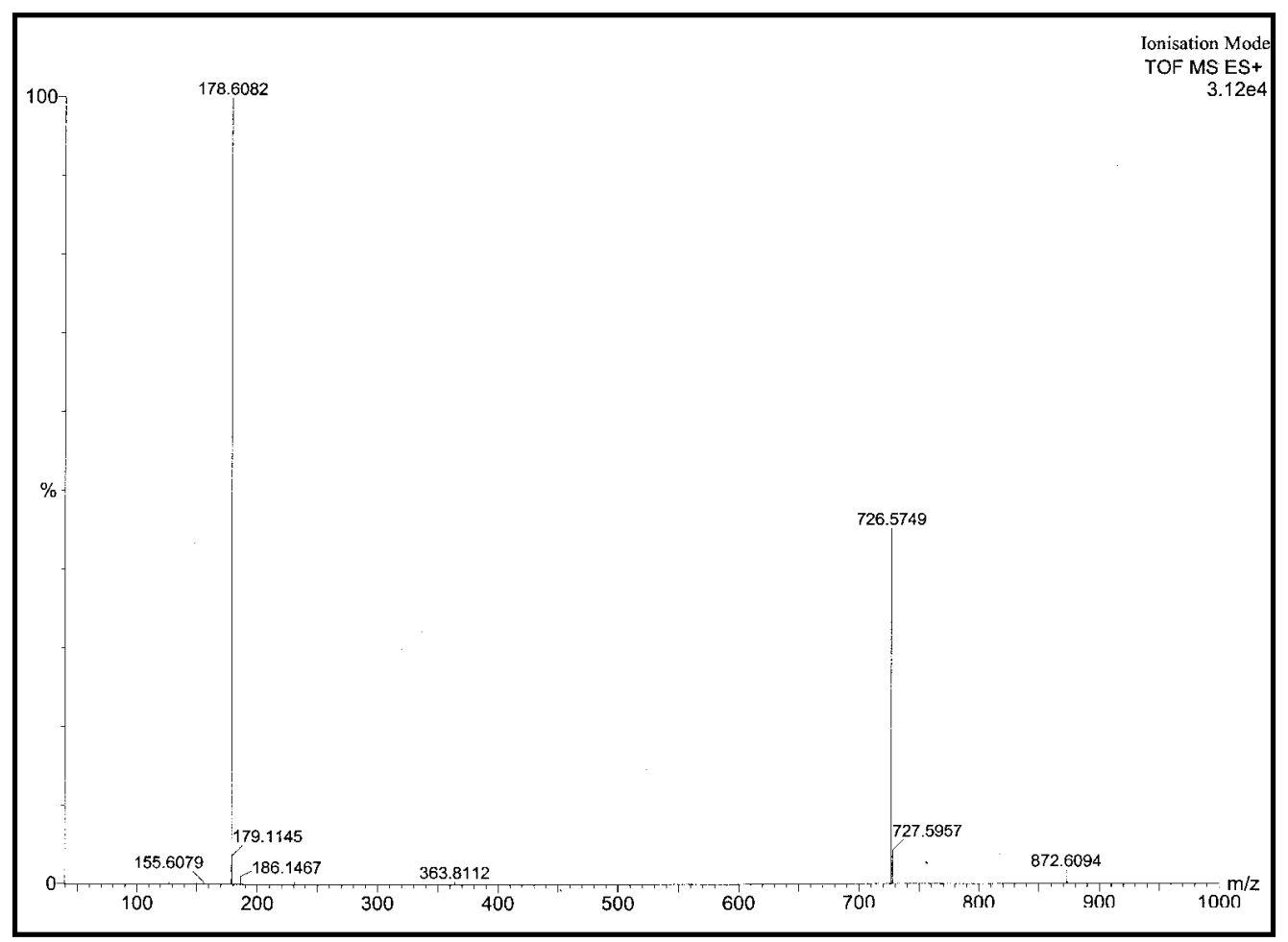

Figure 20: Mass spectrum of compound 10-( $\left.\mathrm{PF}_{6}\right)_{2}$ 


\section{Binding Isotherms}

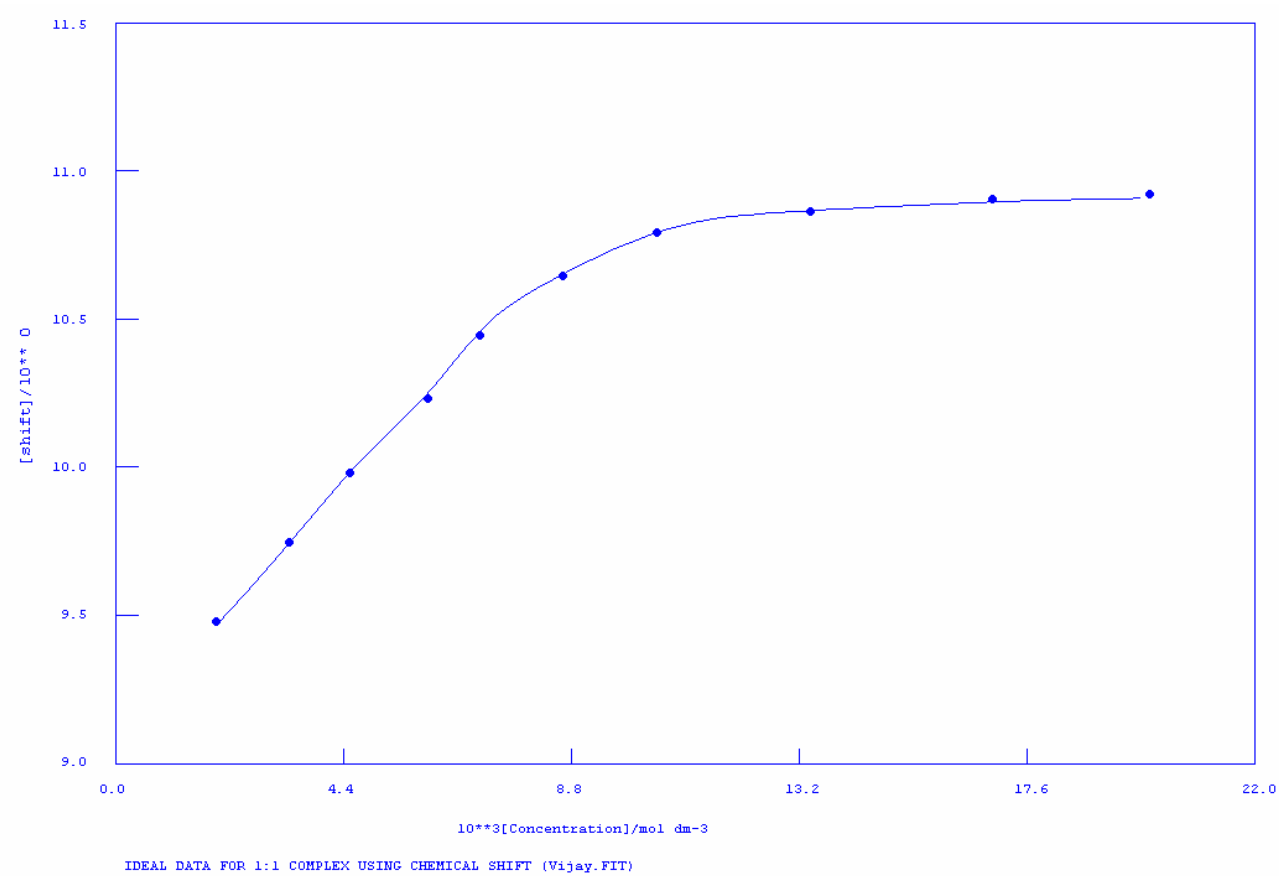

Figure 21: ${ }^{1} \mathrm{H}$ NMR titration binding isotherm for receptor 6 with tetrabutylammonium fluoride (trihydrate salt)

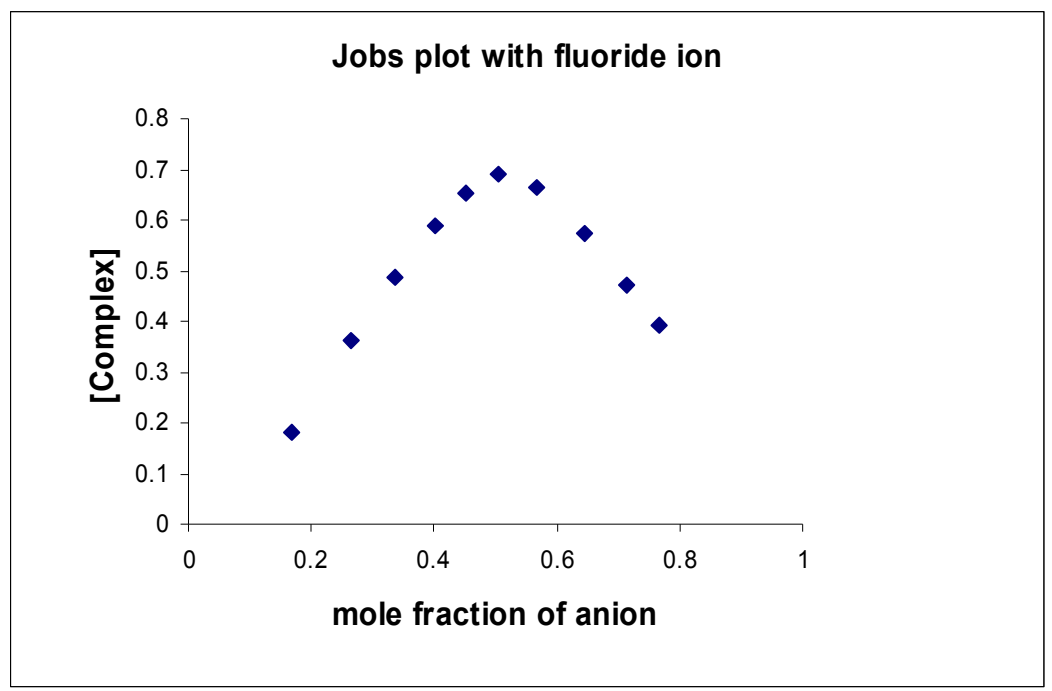

Figure 22: Job's plot showing 1:1 complex formation between receptor 6 and fluoride ion 


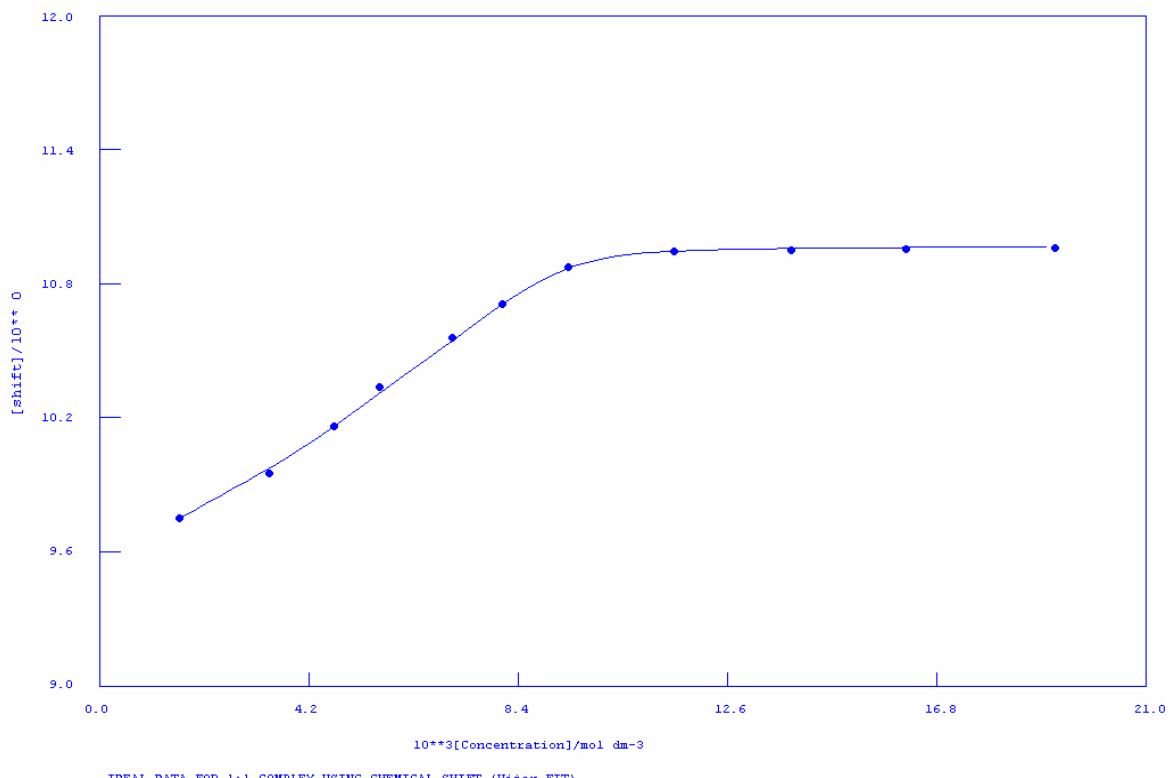

Figure 23: ${ }^{1} \mathrm{H}$ NMR titration binding isotherm for receptor 7 with tetrabutylammonium chloride

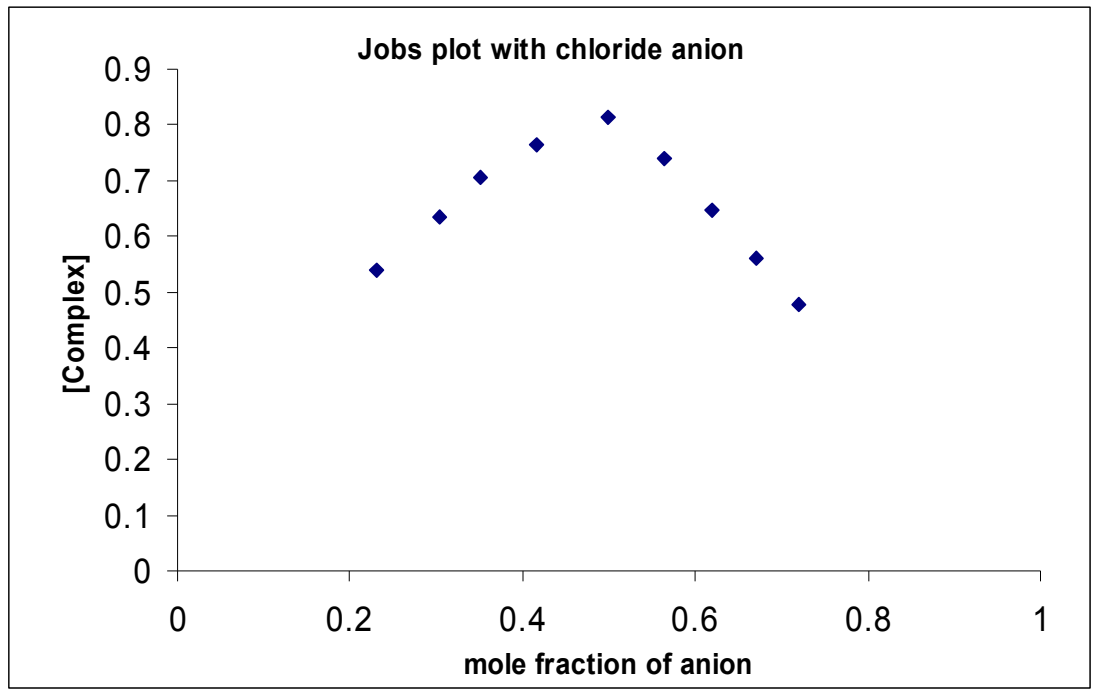

Figure 24: Job's plot showing 1:1 complex formation between receptor 7 and chloride ion 


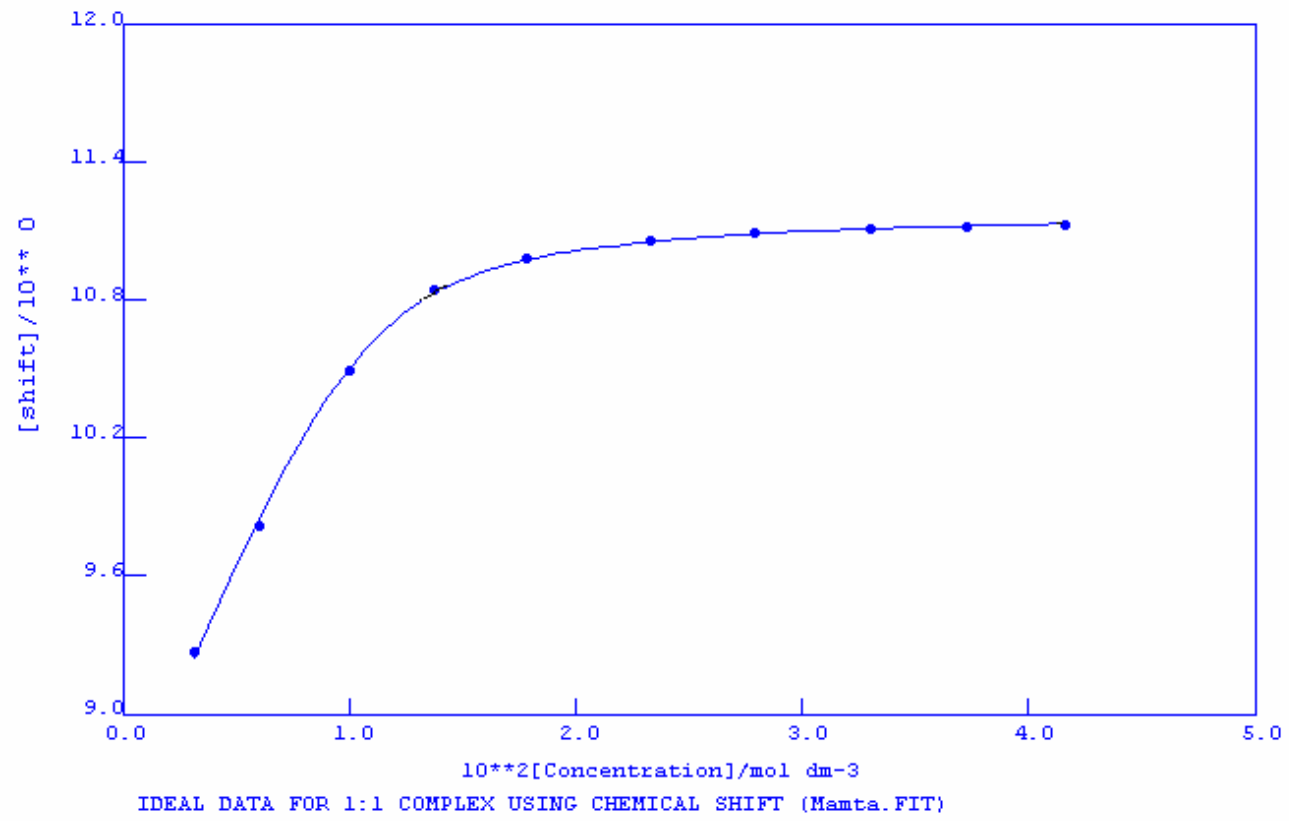

Figure 25: ${ }^{1} \mathrm{H}$ NMR titration binding isotherm for receptor 8 with tetrabutylammonium chloride

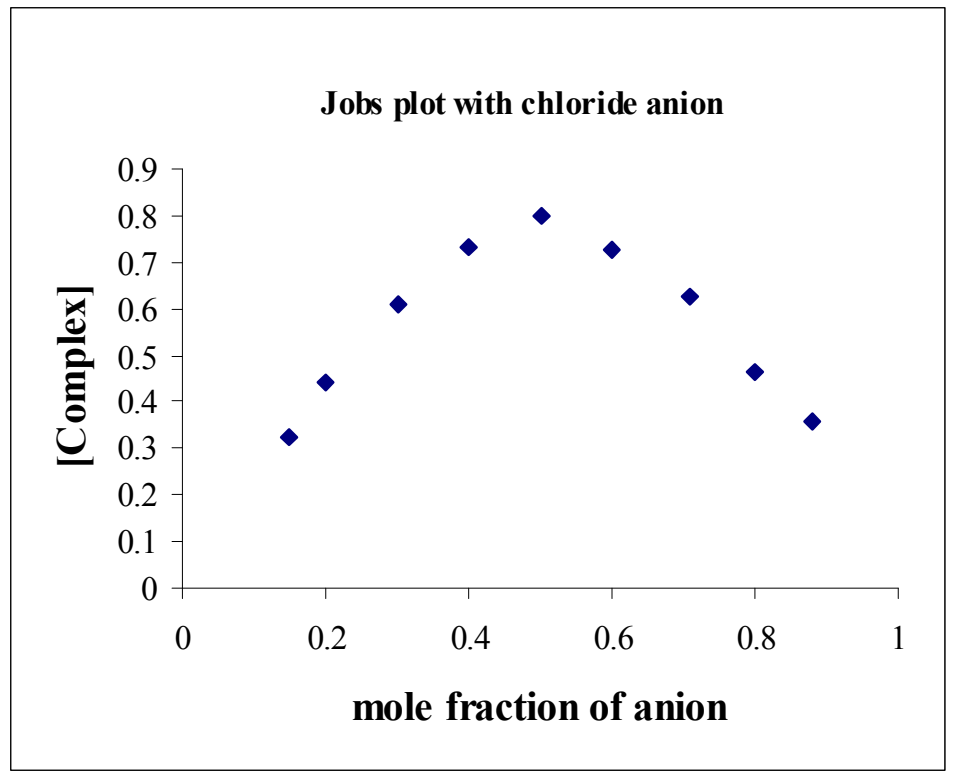

Figure 26: Job's plot showing 1:1 complex formation between receptor 8 and chloride ion 


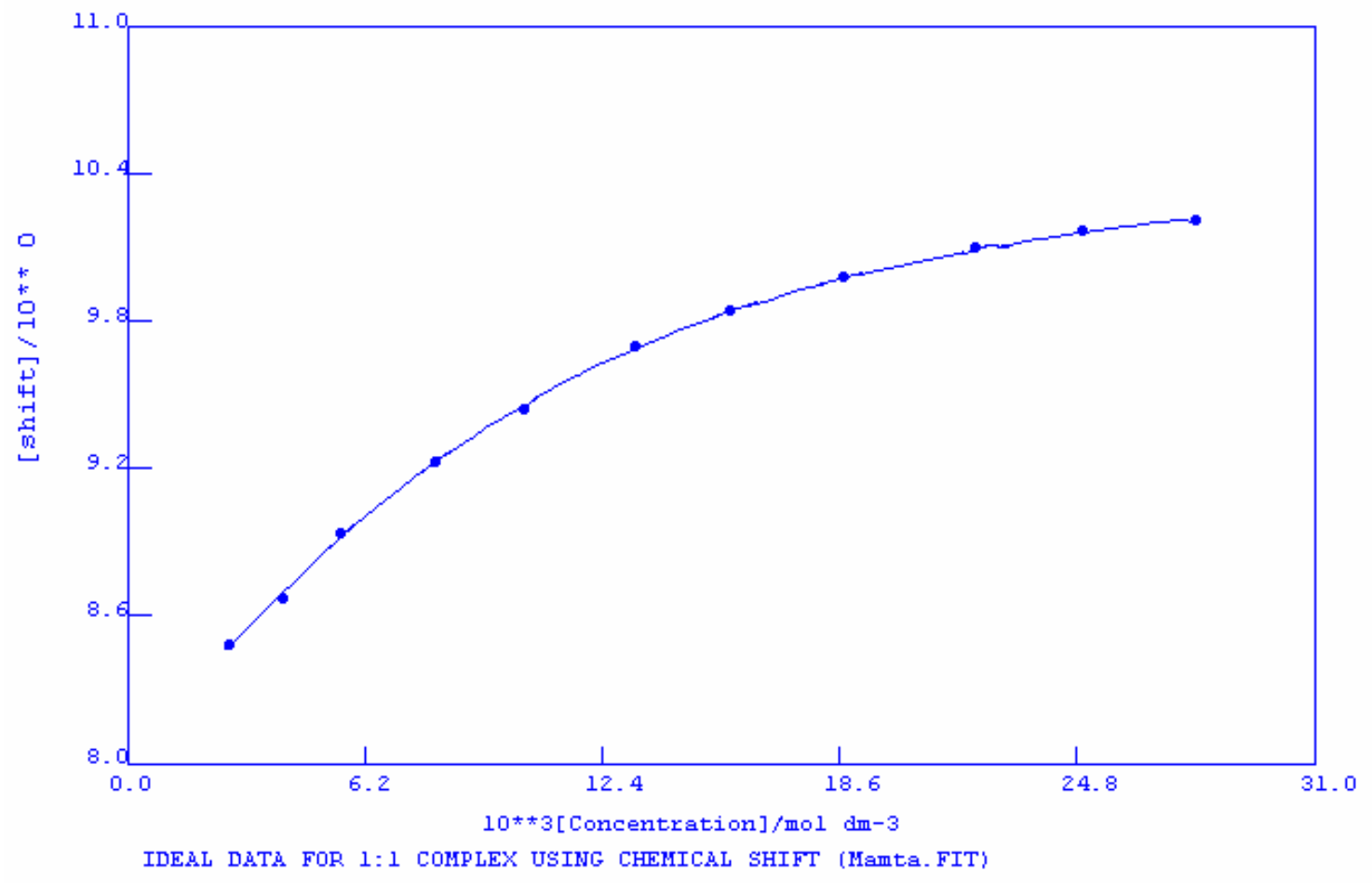

Figure 27: ${ }^{1} \mathrm{H}$ NMR titration binding isotherm for receptor 10 with tetrabutylammonium chloride

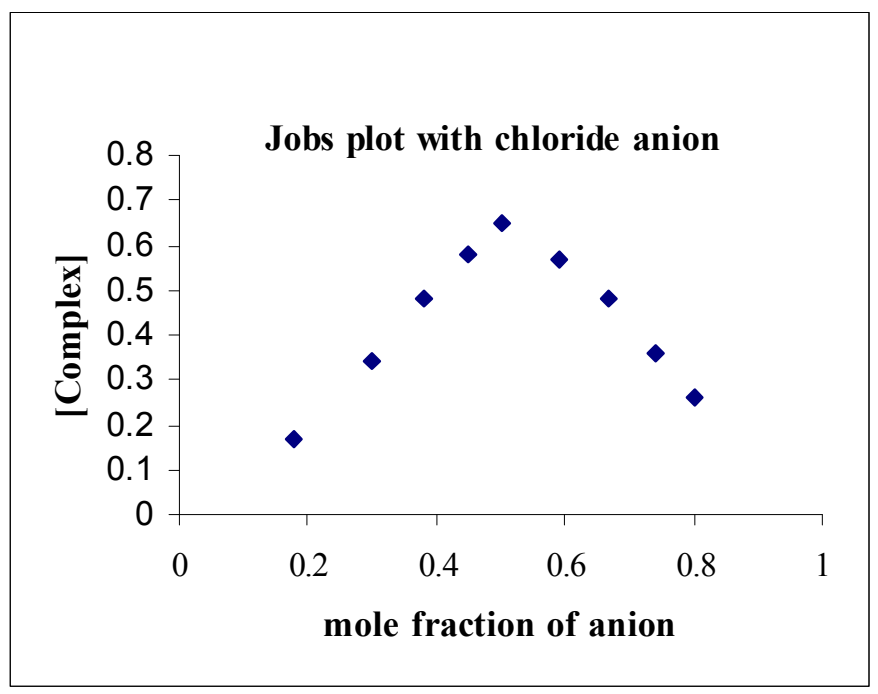

Figure 28: Job's plot showing 1:1 complex formation between receptor 10 and chloride ion 